\title{
La sostenibilidad social de las SATs: una propuesta de indicadores para su evaluación
}

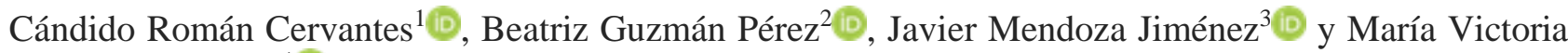 \\ Pérez Monteverde ${ }^{4}$
}

Recibido: 1 de julio de 2019 / Aceptado: 17 de febrero de 2020 / Publicado: 2 de abril de 2020

Resumen. Las entidades del medio rural regidas por los principios de comportamiento de la economía social podrían promover un desarrollo local sostenible en los espacios geográficos en los que se ubican, y contribuir al logro de la sostenibilidad integral a escala global. Para hacer realidad este propósito, se requieren indicadores que permitan su evaluación y seguimiento, y que contemplen los atributos específicos de las distintas familias del tercer sector. Este trabajo tiene por objetivo el planteamiento de métricas que hagan posible monitorizar el valor social para la sostenibilidad de una forma de asociacionismo agrario particular del ordenamiento jurídico español para la que aún no se han diseñado indicadores sociales específicos, las Sociedades Agrarias de Transformación (SATs). El contexto geográfico del estudio es el archipiélago canario, región ultraperiférica de la Unión Europea, e importante destino turístico internacional. De las SATs del conjunto insular, se ha tomado una como caso de estudio, y se ha utilizado la Contabilidad Social como sistema que posibilita el desarrollo de indicadores sociales específicos. La aportación esencial de este trabajo es que plantea métricas que permiten el seguimiento de la contribución a la sostenibilidad social de un grupo de entidades para la cual aún no existen. En desarrollos posteriores, tales indicadores podrían ser testados en otros entes de la misma naturaleza con el objeto de disponer de un conjunto de mínimos aplicable a esta familia de entidades de economía social.

Palabras clave: Economía social; Valor social; Contabilidad social; Sostenibilidad local; Medio rural.

Claves Econlit: B55; M40, K11; Q56.

\section{[en] The social sustainability of the SATs: a proposal of indicators for their evaluation}

\begin{abstract}
Rural entities governed by the behavioral principles of the social economy could promote sustainable local development in the geographical spaces in which they are located and contribute to the achievement of integral sustainability on a global scale. To make this purpose a reality, indicators are needed that allow for their evaluation and follow-up, and that contemplate the specific attributes of the different families of the third sector. The objective of this work is to propose metrics that make possible to monitor the social value for the sustainability of a particular form of agrarian associationism of the Spanish juridical system for which specific social indicators have not yet been designed, the Agrarian Societies of Transformation (AST). The geographical context of the study is the Canary Islands archipelago, an ultraperipheral region of the European Union, and an important international tourist destination. From the ATS of the insular group, one has been taken as a case study, and Social Accounting has been used as a system that enables the development of specific social indicators. The essential contribution of this work is that it establishes metrics that allow the monitoring of the contribution to social sustainability of a group of entities for which they do not yet exist. In later developments, such indicators could be tested in other entities of the same nature in order to have a set of minimums applicable to this family of social economy entities.
\end{abstract}

Keywords: Social economy; Social value; Social accounting; Local sustainability; Rural environmental.

Sumario. 1. Introducción. 2. Marco teórico y objetivos de investigación. 3. Las SATs en Canarias. La contabilidad social. 4. Resultados. 5. Conclusiones. 6. Referencias bibliográficas.

Cómo citar: Román Cervantes, C.; Guzmán Pérez, B.; Mendoza Jiménez, J.; Pérez Monteverde, M.V. (2020) La sostenibilidad social de las SATs: una propuesta de indicadores para su evaluación. REVESCO. Revista de Estudios Cooperativos, vol. 133 , e67336. https://dx.doi.org/10.5209/REVE.67336.

$1 \quad$ Universidad de La Laguna, España

Dirección de correo electrónico: croman@ull.edu.es.

2 Universidad de La Laguna, España

Dirección de correo electrónico: bguzmanp@ull.es.

3 Universidad de La Laguna, España

Dirección de correo electrónico: jmendozj@ull.edu.es.

$4 \quad$ Universidad de La Laguna, España

Dirección de correo electrónico: mvperez@ull.edu.es. 


\section{Introducción}

Las entidades de economía social han sido reconocidas como agentes decisivos en el plan de acción global para el logro de la sostenibilidad integral, tanto en el ámbito institucional (UN, 2015) como académico (Bono, 2012; Chaves y Monzón, 2012). La sostenibilidad local es una pieza clave en dicho proceso global (Tomás, 2008), siendo las áreas rurales territorios críticos de cara a preservar los recursos naturales y sociales (Mozas y Bernal, 2006). La promoción en ellas de actividades económico-productivas que sean sostenibles se torna vital, más aún cuando se integran en territorios insulares con atractivos turísticos (UNWTO, 2012).

Las organizaciones del medio rural regidas por los principios de comportamiento de la economía social podrían promover un desarrollo local sustentable en los espacios geográficos en que se ubican (Bretos y Marcuello, 2016; Mozas y Bernal, 2006). Para hacer efectiva esta aspiración, resulta evidente la necesidad de llevar a cabo una evaluación y seguimiento del desempeño organizacional en materia de sostenibilidad. Esta monitorización orientada a la toma de decisiones exige disponer de indicadores que proporcionen información real sobre la contribución de una entidad a las distintas dimensiones de la sostenibilidad (UN, 2015). Los avances en el diseño de métricas a escala organizacional referidas a los pilares económico y medioambiental han sido sustanciales, mientras que las relativas al ámbito social se encuentran en una fase de desarrollo más incipiente (Ayuso, 2018).

Desde distintas aproximaciones se han planteado sistemas genéricos para la medición del impacto social, valor social o contribución a la sostenibilidad social de una entidad, basados en el diseño de indicadores vinculados a distintos eslabones de la cadena de valor del impacto (Olsen y Galimidi, 2008). Si bien tales herramientas se han aplicado a entidades de economía social, mayoritariamente cooperativas (Etxezarreta et al., 2018) y fundaciones (Ariza-Montes et al., 2018), se ha instado a desarrollar sistemas de evaluación de la sostenibilidad social e indicadores específicos que recojan las particularidades de tales entes (UNTFSSE, 2016). A este respecto, los trabajos de Bassi y Vincenti (2015) y Monzón et al. (2013) dan respuesta a dicho llamamiento, habiendo sido aplicados a cooperativas.

Las Sociedades Agrarias de Transformación (SATs) son una fórmula del asociacionismo agrario peculiar del ordenamiento jurídico español, que presenta diferencias con respecto al agente de economía social al que la literatura científica ha prestado mayor atención, la sociedad cooperativa (Bel Durán, 1995). El planteamiento de indicadores que permitan monitorizar el desempeño social de estas entidades no ha sido abordado. Este trabajo viene a suplir esta carencia relativa, y plantea como objetivo principal el diseño de métricas del valor social para la sostenibilidad específicas de estas organizaciones. El contexto geográfico del estudio es el archipiélago canario, parte del análisis de una de las SATs en él registradas, y hace uso del sistema de medición del valor social de la Contabilidad Social (Retolaza et al., 2016) para el planteamiento de indicadores específicos del desempeño de esta familia de entidades de economía social.

La estructura de este estudio es la siguiente. En el apartado 2 se contextualiza en la literatura científica, mostrando una síntesis de la revisión de los trabajos que, desde distintos enfoques, abordan la problemática que aquí ocupa: las entidades de economía social como agentes de desarrollo sostenible, el diseño de indicadores para el seguimiento de la contribución a la sostenibilidad social, y las sociedades agrarias de transformación, planteándose también los objetivos de investigación. En el apartado 3 se describe a la población, el caso de análisis, y el sistema de la Contabilidad Social (Retolaza et al., 2016). Los resultados alcanzados se exponen en el apartado 4 y, en el 5, la discusión y conclusiones.

\section{Marco teórico y objetivos de investigación}

\subsection{El desarrollo sostenible y las entidades de economía social}

Desde un enfoque institucional, el desarrollo sostenible ha sido definido como la capacidad para satisfacer las necesidades del presente sin comprometer la capacidad de las generaciones futuras para satisfacer sus propias necesidades (World Commission on Environment and Development 1987), teniendo en cuenta una triple dimensión medioambiental, económica y social (UN 2002). El movimiento internacional comprometido con la sostenibilidad ha quedado materializado en la Agenda 2030 de Desarrollo Sostenible (UN 2015), aprobada en la Cumbre del Desarrollo Sostenible de 2015 e integrada por 17 objetivos de aplicación universal, relacionados con cinco esferas consideradas críticas para la humanidad y el planeta ${ }^{5}$. Desde 2016, dichos objetivos, y sus correspondientes metas, vienen dirigiendo los esfuerzos de los países para lograr un mundo sostenible en el año 2030. 
Las entidades de economía social han sido reconocidas como agentes decisivos en dicho plan de acción global encaminado al logro de la sostenibilidad integral, tanto en el ámbito institucional (UN 2015) como académico, fundamentalmente por los dos motivos que a continuación se exponen. En primer lugar, porque los principios de funcionamiento de las organizaciones de economía social, recogidos en la Carta de Principios de la Economía Social aprobada en 2002 por el Comité Europeo Permanente de las Cooperativas, las Mutualidades, las Asociaciones y las Fundaciones (CEP-CMAF), están alineados con los valores que orientan el desarrollo sostenible (Utting, 2015), por lo que podrían promover el modelo de desarrollo humano e integral que se pretende (UNTFSSE 2016).

En particular, la priorización de las personas y el trabajo frente al capital, el propósito social o la gobernanza democrática que caracterizan a estas entidades podrían posibilitar el ejercicio de unas funciones sociales, económicas y políticas en el sistema económico que contribuirían al logro de un crecimiento sustentable y socialmente integrador ${ }^{6}$ (Bono, 2012; Chaves y Monzón, 2012; Macías, 2018). Las instituciones internacionales han precisado a su vez las metas específicas que, dentro de cada uno de los objetivos de desarrollo sostenible, se verían reforzadas a través de su actuación (Utting 2015).

El segundo motivo por el que estos agentes se estiman críticos para el logro de los retos planteados está relacionado con el ámbito en el que despliegan su actividad. A este respecto, su arraigo en la economía local y la comunidad en la que operan favorecería que, a este nivel territorial, el desarrollo humano e inclusivo fuese una realidad (UNTFSSE 2016). La consideración de las demandas y necesidades locales y su consecución en la práctica supone un aspecto de suma importancia para hacer efectivo el desarrollo centrado en las personas ${ }^{7}$.

Teniendo, pues, presente que la sostenibilidad a escala local es, con carácter general, una pieza clave en el proceso global -por las capacidades estratégicas en las que se basa (Tomás, 2008)-, y que, en particular, las áreas rurales son territorios especialmente críticos de cara a preservar los recursos naturales y sociales (Mozas y Bernal, 2006), la promoción en las mismas de actividades económico-productivas que sean sustentables se torna vital, más aún cuando se integran en territorios insulares con atractivos turísticos (UNWTO, 2012). En estos espacios, la visión estratégica del modelo tradicional de desarrollo desataría una competencia espacial (Tomás, 2008) que, además de entrañar riesgos ecológicos (Neto, 2003), acrecentaría los desequilibrios sociales y económicos (Bono, 2012).

En este contexto, las entidades del medio rural regidas por los principios de comportamiento de la economía social podrían promover un desarrollo local sustentable en las áreas geográficas en las que se ubican (Bretos y Marcuello, 2016; Mozas y Bernal, 2006). Concretamente, la fórmula organizativa mayormente estudiada, el cooperativismo en la cadena agroalimentaria o en el turismo rural (Flores y $\mathrm{O}$ Barroso, 2011; Puentes y Velasco, 2009), actuaría reforzando la fijación de la población al territorio, posibilitando la participación democrática de los socios, favoreciendo la continuidad y permanencia temporal de la actividad productiva y fomentando la formación, la continuidad en el empleo o la cohesión económica y social.

\subsection{La evaluación de la sostenibilidad del desarrollo: el sistema de indicadores}

El cumplimiento de los compromisos adquiridos en el horizonte planteado exige la evaluación y el seguimiento de los objetivos establecidos, no sólo para orientar la toma de decisiones sino también hacer posible la rendición de cuentas a la ciudadanía. Se precisan, pues, indicadores o "representaciones simbólicas diseñadas para comunicar una propiedad o tendencia de un sistema o entidad compleja" (Moldan y Dahl, 2007:1), que sean reflejo fiel, en este caso, del grado de sostenibilidad alcanzado. A este respecto, resulta crítico que tales indicadores proporcionen información del estado de situación real, y permitan guiar la acción en la dirección adecuada (Meadows, 1998).

Para el diseño específico del conjunto de indicadores en esta materia, ha de tenerse presente la propia definición de desarrollo sostenible y, en consecuencia, el modelo ético en el que se fundamenta ${ }^{8}$. El valor central de este "desarrollo del sistema humano, social y económico, capaz de mantenerse indefinidamente en armonía con los sistemas biofísicos del planeta" (Moldan y Dahl, 2007:2) es la dignidad humana (Aguado et al., 2015; Cortina, 2009), siendo esencialmente los principios de libertad en los medios y fines (Sen, 1999), justicia intergeneracional e intrageneracional y desarrollo de las capacidades humanas (Nussbaum, 1997, 2011), los que lo vertebran.

6 Los patrones de producción, finanzas e intercambio de las entidades de economía social priorizan no sólo a las personas, sino también el respeto del entorno natural. Se estima que su actuación reforzaría de forma holística y sinérgica las distintas dimensiones de la sostenibilidad, y constituirían una alternativa al modelo de desarrollo desequilibrado y excluyente, derivado de la centralidad del pilar económico.

Una de las limitaciones encontradas durante la aplicación de los Objetivos de Desarrollo del Milenio, predecesores de los actuales Objetivos de Desarrollo Sostenible, fue su definición global y nacional, pasando por alto las demandas locales y, por tanto, el nivel de consecución de los objetivos a este nivel.

8 En última instancia, los indicadores se diseñan para obtener una medida de los aspectos que preocupan a una sociedad, de sus principios y valores, por lo que tales indicadores deben ser también reflejo de estos últimos (Meadows, 1998). 
La complejidad que conllevaría la construcción de indicadores que permitan disponer de información real sobre la sostenibilidad del sistema, podría abordarse planteando marcos que permitan conocer no sólo el estado de cada uno de tres pilares de la sostenibilidad por separado, sino también el que resulta de su integración y de los valores subyacentes (Moldan y Dahl, 2007). A este respecto, resulta útil la propuesta de Meadows (1998) (Figura 1), basada en una representación piramidal de la interrelación entre economía y naturaleza (Daly, 1977), conformada por los cuatro niveles siguientes.

Figura. 1. Marco para el diseño de indicadores de sostenibilidad.

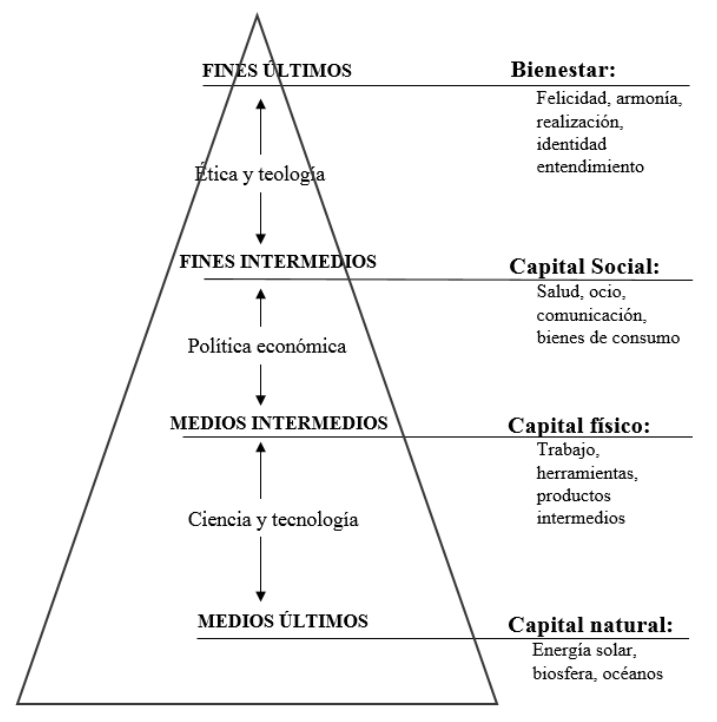

Fuente: Adaptado de Meadows (1998: 42).

En un primer nivel se encuentran los medios últimos o capital natural, que incluye los elementos presentes originariamente en el planeta, y que sirven de sustento a la actividad económica. Sobre éstos actúa la ciencia y la tecnología, transformándolos en medios intermedios o capital físico, segundo nivel de la pirámide. Dicho nivel es el que determina la capacidad productiva de la economía, conteniendo los inputs económicos tradicionales que, si bien necesarios, no son suficientes para garantizar el desarrollo humano. La valoración, distribución y gestión de tales factores de producción, a través de la política económica, permite alcanzar el tercer nivel, el de los fines intermedios, outputs o bienes económicos -salud, conocimiento, bienes de consumo, transporte, comunicación-. Su posesión tampoco garantiza la satisfacción humana, al no ser fines en sí mismos. Para alcanzar el fin último, o bienestar humano, es preciso la intervención de la ética, religión o filosofía, puesto que es la que permite entender cómo lograr un estado de plenitud o armonía a través de los bienes económicos.

Sobre la base de este modelo, sería necesario diseñar indicadores que informasen tanto de la situación de cada nivel de la pirámide o pilar de la sostenibilidad, como de las conexiones entre los mismos, y mostrar, en última instancia, en qué medida se consigue proveer de la misma cantidad de fines últimos e intermedios movilizando una menor cantidad de medios finales o intermedios, a través de la intervención equilibrada e integral de la tecnología, la política económica y la ética y la filosofía.

Con carácter general, se ha logrado avanzar en menor medida en el desarrollo de indicadores que permitan evaluar aspectos cualitativos, inherentes a los fines últimos y al capital social (tolerancia, confianza, seguridad, creatividad), que, en los referidos a aspectos cuantitativos, mayoritariamente presentes en el capital físico y natural (Meadows, 1998). Para cubrir esta brecha, se ha reconocido la utilidad del empleo de proxys o indicadores sustitutivos para obtener, al menos, una medida de vasta o ruda de aspectos complejos ${ }^{9}$ (Moldan y Dahl, 2007).

En cuanto a otros aspectos que, de forma específica, deben tomarse en consideración en el diseño de los indicadores de sostenibilidad (Meadows, 1998; Moldan y Dahl, 2007), pueden resaltarse los siguientes: (a) han de ser entendibles y de fácil comprensión para una gran diversidad de stakeholders; (b) deben proporcionar información con distinto nivel de agregación -global, nacional, regional o sub-regional-; y (c) ser inclusivos, participativos y transparentes (UN, 2015). Se ha adoptado un marco de indicadores mundiales

9 Por ejemplo, puede medirse el estado de situación del "cambio climático en el planeta en un momento del tiempo" empleando como proxy el volumen en toneladas de emisiones de $\mathrm{CO}_{2}$. 
para los objetivos y metas de desarrollo sostenible que permiten monitorizar el progreso a escala global y nacional ${ }^{10}$ (UN, 2017). Por su parte, las redes nacionales para el desarrollo sostenible, en colaboración con las Naciones Unidas, se ocupan del planteamiento de indicadores de ámbito regional y sub-regional.

Para evaluar la contribución a la sostenibilidad a nivel organizacional ${ }^{11}$, resulta necesario el establecimiento de indicadores específicos que, para esta escala de desagregación, lo hagan posible. A este respecto, si bien los progresos alcanzados en el planteamiento de métricas referidas a las dimensiones económica ${ }^{12}$ y medioambiental ${ }^{13}$ han sido sustanciales, las relativas a la vertiente social están en una fase de desarrollo más incipiente. Un marco de referencia ampliamente consensuado para el planteamiento de indicadores que, a esta escala de desagregación, reflejen dicho pilar de sostenibilidad es el modelo de la cadena de valor del impacto, teoría del cambio o modelo lógico (Olsen y Galimidi, 2008). Dicho modelo recoge la cadena de causalidad por la que las actividades de una organización se traducen en impactos sociales (Figura 2).

Figura. 2. Modelo de la cadena de valor del impacto.

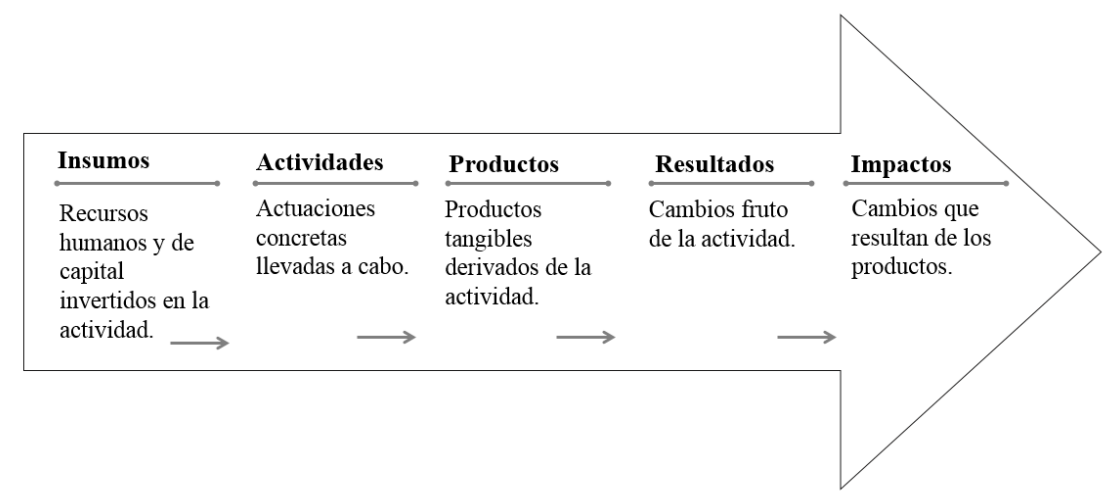

Fuente: Adaptado de Olsen y Galimidi (2008).

El primer eslabón del proceso de cambio es el de los insumos, o totalidad de recursos, humanos o de capital, invertidos en las actividades de una organización. El segundo, el de las propias actividades, es decir, aquellas acciones concretas, tareas y trabajos llevados a cabo por la organización para generar productos y resultados y alcanzar objetivos. Los outputs constituyen el tercer eslabón, referido a los bienes y servicios tangibles que resultan de las actividades llevadas a cabo por la entidad. En cuarto lugar, los outcomes o resultados, definidos como los cambios, beneficios, aprendizajes u otros efectos, tanto a corto como a largo plazo, que resultan de las actividades de la organización. Por último, el impacto social, definido como la parte de las actividades de una organización atribuible a los resultados más generales a largo plazo, teniendo en cuenta los efectos de ajuste ${ }^{14}$. Las métricas requeridas para reflejar los logros alcanzados por una organización en el ámbito de la sostenibilidad social habrían de referirse a los impactos, o a aquellas actividades o outputs de la entidad que han promovido tales impactos o cambios sociales ${ }^{15}$.

10 Si bien el propio planteamiento de tales indicadores a escala global supone un avance considerable, desde determinados enfoques se considera que tales indicadores son insuficientes para evaluar los avances logrados y orientar la toma de decisiones.

11 Las organizaciones, en su interacción con la realidad y el medio que les rodea, establecen flujos reales, financieros y de información con sus stakeholders (Freeman, 1984). Independientemente de que su propósito sea la obtención de la máxima rentabilidad para los propietarios del capital (Friedman, 1970), la creación de valor para los grupos de interés (Freeman et al., 2004) o la influencia trascendente en la sociedad de la que forman parte (Duska y Ragatz, 2008; Melé, 2009), lo cierto es que, con el ejercicio de su actividad económico-productiva, generan utilidades, de naturaleza económico-financiera para los accionistas, y socio-económicas y medioambientales para la comunidad local (Emerson et al., 2003; Porter y Kramer, 2011). Los trabajos científicos suelen referirse a esta incidencia de las organizaciones en la sociedad con los términos de impacto socio-económico (Monzón, 2013), impacto social (Olsen y Galimidi, 2008), valor compartido (Porter y Kramer, 2011) o valor social (Bassi y Vincenti, 2015; Retolaza et al., 2016; Tuan, 2008).

12 Para medir la sostenibilidad económica de una entidad, suele ser habitual el empleo de indicadores de naturaleza financiera, diseñados a partir de la cuenta de resultados e informes financieros de la propia organización (Ayuso, 2018).

13 Existen varias metodologías estandarizadas que integran métricas para determinar la sostenibilidad ambiental de una entidad, como por ejemplo, la norma ISO 14040 de Análisis de Ciclo de Vida, o el GHG Protocol para el cálculo de las emisiones de gases de efecto invernadero (Ayuso, 2018).

14 Para calcular de forma precisa y rigurosa el impacto social de una entidad habrían de tenerse en cuenta los siguientes efectos de ajuste (AEF, 2015): (a) el peso muerto, o qué hubiera sucedido de todas maneras; (b) la atribución, es decir, la acción de otros; (c) el decrecimiento, esto es, hasta qué punto y cómo el resultado de la intervención inicial se reducirá con el tiempo; (d) el desplazamiento, o hasta qué punto la situación original se ha desplazado hacia otro lugar, o los resultados han desviado otros potenciales resultados positivos; y (e) las consecuencias no intencionadas, que pueden ser negativas o positivas.

15 Por ejemplo, iniciativas como fomentar la participación de los trabajadores en la toma de decisiones puede ayudar a crear cohesión social. 
Desde distintos enfoques se han propuesto sistemas genéricos para determinar el impacto social a escala organizacional (Ayuso, 2018), como son el Balance del Bien Común (Felber, 2010), la Evaluación de Impacto B, (Honeyman et al., 2014), el modelo LBG, desarrollado por un grupo de empresas del Reino Unido, el Índice de Capacidades (Garriga, 2014), el Marco para la Medición de Impacto, desarrollada por World Business Council for Sustainable Development, (WBCSD/IFC, 2008), la Contabilidad Social (Retolaza et al., 2014), o el Retorno Social de la Inversión, S.R.O.I., desarrollado por el fondo estadounidense Roberts Enterprise Development Fund, REDF. Estos sistemas han sido aplicados a diversas familias de entidades de economía social, como centros especiales de empleo (Can Cet, 2016), empresas sociales (B Lab 2017), cooperativas (Etxezarreta et al., 2018), o fundaciones (Ariza-Montes et al., 2018).

Cada una de estas herramientas mide el impacto social centrándose en distintos eslabones de la cadena de la gestión del impacto, y plantean métricas referidas a diferentes fases del modelo lógico. Asimismo, la naturaleza de los datos requeridos para la determinación de los indicadores y el grado de participación de los stakeholders en el proceso de evaluación varía entre los sistemas. En la Tabla 1 se muestran las diferencias existentes referidas a estos aspectos.

Tabla. 1. Sistemas de medición del impacto social.

\begin{tabular}{|c|c|c|c|c|}
\hline Sistema & Objeto & Indicadores & $\begin{array}{l}\text { Participación de } \\
\text { stakeholders }\end{array}$ & $\begin{array}{l}\text { Requerimiento } \\
\text { de datos }\end{array}$ \\
\hline $\begin{array}{l}\text { Balance del Bien } \\
\text { Común }\end{array}$ & \begin{tabular}{lrr}
\multicolumn{3}{l}{ Medir el grado en que } \\
las entidades \\
contribuyen con & sus \\
actuaciones a & la \\
generación de & bien \\
común a & los \\
stakeholders. & \\
\end{tabular} & Actividades & Voluntaria & Internos \\
\hline $\begin{array}{l}\text { Evaluación } \\
\text { Impacto B }\end{array}$ & $\begin{array}{l}\text { Evaluar el desempeño } \\
\text { social y ambiental de } \\
\text { una empresa. }\end{array}$ & $\begin{array}{l}\text { Insumos, actividades } \\
\text { y outputs. }\end{array}$ & No participan & Internos \\
\hline Modelo LBG & $\begin{array}{l}\text { Medir los impactos de } \\
\text { la acción social } \\
\text { empresarial voluntaria } \\
\text { y caritativa. }\end{array}$ & $\begin{array}{l}\text { Insumos, outputs e } \\
\text { impactos. }\end{array}$ & $\begin{array}{l}\text { Participan las } \\
\text { entidades } \\
\text { colaboradoras }\end{array}$ & $\begin{array}{l}\text { Internos y de las } \\
\text { entidades } \\
\text { colaboradoras. }\end{array}$ \\
\hline $\begin{array}{ll}\text { Marco para } & \text { la } \\
\text { Medición } & \text { de } \\
\text { Impacto } & \\
\end{array}$ & $\begin{array}{l}\text { Evaluar el impacto } \\
\text { social de una entidad } \\
\text { en la comunidad. }\end{array}$ & $\begin{array}{l}\text { Impactos -directos e } \\
\text { indirectos. }\end{array}$ & $\begin{array}{l}\text { Voluntaria, } \\
\text { aunque } \\
\text { recomendable }\end{array}$ & $\begin{array}{l}\text { Internos } \\
\text { encuestas }\end{array}$ \\
\hline $\begin{array}{ll}\text { Índice } & \text { de } \\
\text { Capacidades } & \end{array}$ & $\begin{array}{l}\text { Impacto social de un } \\
\text { proyecto de cierta } \\
\text { duración. }\end{array}$ & $\begin{array}{l}\text { Insumos, actividades, } \\
\text { outputs, resultados e } \\
\text { impactos }\end{array}$ & Indispensable & $\begin{array}{l}\text { Internos, } \\
\text { encuestas } \\
\text { fuentes } \\
\text { secundarias }\end{array}$ \\
\hline $\begin{array}{l}\text { Contabilidad } \\
\text { Social }\end{array}$ & $\begin{array}{l}\text { Medir el valor social } \\
\text { percibido por los } \\
\text { stakeholders de la } \\
\text { organización }\end{array}$ & $\begin{array}{l}\text { Inputs con coste de } \\
\text { oportunidad directo, } \\
\text { resultados percibidos } \\
\text { como impacto, } \\
\text { outputs que se } \\
\text { transforman en } \\
\text { resultados o impactos }\end{array}$ & Indispensable & $\begin{array}{l}\text { Internos, fuentes } \\
\text { secundarias, } \\
\text { encuestas. }\end{array}$ \\
\hline $\begin{array}{l}\text { Retorno Social de } \\
\text { la Inversión }\end{array}$ & $\begin{array}{l}\text { Medir el valor social y } \\
\text { medioambiental } \\
\text { generado por una } \\
\text { actividad o proyecto }\end{array}$ & $\begin{array}{l}\text { Insumos, actividades, } \\
\text { outputs, resultados e } \\
\text { impactos, teniendo en } \\
\text { cuenta los efectos de } \\
\text { ajuste }\end{array}$ & Indispensable & $\begin{array}{l}\text { Internos, fuentes } \\
\text { secundarias y } \\
\text { encuestas }\end{array}$ \\
\hline
\end{tabular}

Fuente: Elaboración propia, basada en Ayuso (2018).

Desde el ámbito institucional internacional, se ha instado al desarrollo de sistemas y métricas específicos para las entidades de Economía Social (UNTFSSE 2016) que permitan tener en cuenta no sólo los atributos que las diferencian de las organizaciones empresariales, sino también la propia diversidad interna del Tercer Sector. A este respecto, se han planteado el Social Added Value Evaluation, S.A.V.E. (Bassi y Vincenti, 2015), para entidades sin ánimo de lucro y empresas sociales, habiéndose aplicado a cooperativas sociales 
italianas, o el Key Performance Indicators, KPIs, (Monzón et al., 2013), dirigido a empresas sociales y aplicado también a cooperativas. En la Tabla 2 se recogen sus características principales.

Tabla. 2. Sistemas de medición del impacto social planteados para entidades de Economía Social.

\begin{tabular}{l|l|l|l|l}
\hline Sistema & Objeto & Indicadores & $\begin{array}{l}\text { Participación de } \\
\text { stakeholders }\end{array}$ & $\begin{array}{l}\text { Requerimiento } \\
\text { de datos }\end{array}$ \\
\hline $\begin{array}{l}\text { Social Added } \\
\text { Value Evaluation }\end{array}$ & $\begin{array}{l}\text { Medir el valor } \\
\text { social añadido de } \\
\text { organizaciones sin } \\
\text { fin de lucro y } \\
\text { empresas sociales }\end{array}$ & $\begin{array}{l}\text { Insumos, actividades, } \\
\text { outputs, resultados e } \\
\text { impactos }\end{array}$ & Indispensable & $\begin{array}{l}\text { Internos, fuentes } \\
\text { secundarias y } \\
\text { encuestas }\end{array}$ \\
\hline $\begin{array}{l}\text { Key Performance } \\
\text { Indicators }\end{array}$ & $\begin{array}{l}\text { Medir el impacto } \\
\text { social de empresas } \\
\text { sociales }\end{array}$ & $\begin{array}{l}\text { Insumos, actividades, } \\
\text { outputs, resultados e } \\
\text { impactos }\end{array}$ & Indispensable & $\begin{array}{l}\text { Internos, fuentes } \\
\text { secundarias y } \\
\text { encuestas }\end{array}$ \\
\hline
\end{tabular}

Fuente: Elaboración propia.

\subsection{Las Sociedades Agrarias de Transformación}

La Ley 5/2011 de Economía Social reconoce a las Sociedades Agrarias de Transformación (SATs) como agentes del Tercer Sector, por poseer unos rasgos de comportamiento alienados con los principios orientadores de la Economía Social. La fórmula organizativa y de gestión que caracteriza a dichas sociedades, aunque basada en el asociacionismo, es específica del ordenamiento jurídico español ${ }^{16}$ (VargasVasserot, 2009). En concreto, su marco regulador, el Real Decreto 1776/1981 y su Orden correspondiente, las configura como sociedades civiles en el sector agropecuario, con fines de naturaleza económica y social. Los primeros se concretan en la producción, transformación y distribución de productos agrícolas, ganaderos y forestales. Los de índole social están referidos a la realización de mejoras en el medio rural, la promoción y desarrollo agrarios y la prestación de servicios comunes que sirvan a aquella finalidad, como el seguro agrario, el crédito o el asesoramiento (Bel Durán, 1995).

Esta figura asociativa tiene sus antecedentes en los Grupos Sindicales de Colonización Agraria (GSC), creados tras la Guerra Civil española con la Ley de Colonización de Interés Local de 25 de noviembre de 1940 (Vargas-Vasserot, 2009). Originariamente fueron concebidos para la realización de actividades de mejora en zonas rurales y promoción de obras y actividades agrarias con el auxilio del Estado. No obstante, diversas órdenes y circulares posteriores ampliaron su campo de acción (Bel Durán, 1995), dotándolos de un carácter societario, cooperativo y mercantil. Con esta conjunción del trabajo en grupo y la búsqueda del interés individual se pretendía incrementar la productividad en el sector agropecuario español (RománCervantes, 2008).

Los GSC alcanzaron una gran difusión, especialmente a partir de los años sesenta del pasado siglo ${ }^{17}$ (Carbonell de Masy y Paniagua, 1974). Se advierte, no obstante, la necesidad de introducir cambios en su regulación que recogiesen la nueva realidad política y económica del país (Vargas, 2009). A este respecto, la promulgación del Real Decreto-Ley 31/1977 eliminó la sindicación obligatoria y facultó al Gobierno para regular y adaptar los grupos sindicales a las nuevas sociedades agrarias de transformación, creadas con el mismo (Bel Durán, 1995).

El estatuto de las SATs, aprobado por el Real Decreto 1776/1981, fue diseñado tomando como referencia el de la agrupación sindical recién extinguida ${ }^{18}$, confluyendo en él elementos propios de la cooperación y de las entidades mercantiles (Román-Cervantes, 2008). Las características jurídicas de estas sociedades agrarias han sido analizadas en profundidad por la corriente de la literatura especializada en la materia ${ }^{19}$, destacándose en este estudio las siguientes:

16 En Francia existe una figura asociativa que presenta similitudes con la española, denominada Groupements Agricoles d' Explotation en Comun (GAEC) (Román-Cervantes, 2008).

17 Fundamentalmente, por el incremento de subvenciones estatales que les fueron asignadas por la Orden Ministerial de 25 de junio de 1963 (Román-Cervantes, 2008).

18 Según Román-Cervantes (2008), se consideraba que el modelo subyacente a los GSC permitiría al sector agropecuario español responder con efectividad a los retos que conllevaba su integración en la Comunidad Económica Europea.

19 Puede consultarse Bel Durán (1995), Gadea (1996), Mauleón y Genovart (2015), Paz Canalejo (1994), o Vargas-Vasserot (2009, 2012) para una revisión profunda de las características jurídicas de las SATs. Por su parte, el estudio histórico de Román Cervantes (2008) adopta una perspectiva comparativa de la SAT, con la sociedad cooperativa y la sociedad anónima, para situar a dicha figura en la Economía Social. 
- $\quad$ Para su constitución se requieren al menos $3 \operatorname{socios}^{20}$, adquiriendo personalidad jurídica y plena capacidad de obrar mediante su inscripción en el Registro General de las SATs, o en el de la Comunidad Autónoma correspondiente ${ }^{21}$.

Con carácter general, puede considerarse que la gestión de estas entidades es democrática, adoptándose la mayor parte de los acuerdos siguiendo el principio cooperativo " 1 hombre, 1 voto" (CIRIEC, 1995). No obstante, los Estatutos pueden establecer la proporcionalidad de votos respecto a las aportaciones al capital social (Bel Durán, 1995), en los acuerdos que supongan obligaciones económicas para los $\operatorname{socios}^{22}$. Debe tenerse en cuenta, sin embargo, que la aprobación de los Estatutos corresponde al órgano supremo de representación de la voluntad de los socios, la Asamblea General, para lo cual dispone de plena autonomía ${ }^{23}$.

En estas asociaciones, el reparto de beneficios se lleva a cabo atendiendo a la aportación efectuada por el socio al capital social, y no en función de su contribución al flujo real de la entidad ${ }^{24}$. A su vez, no están legalmente obligadas a de realizar dotaciones a fondos de reserva, educación, o de obras sociales, ni limitadas para poder realizar operaciones propias de su actividad con terceras personas ${ }^{25}$ (Bel Durán, 1995; Román-Cervantes, 2008).

Por último, son sociedades en las que prevalece la figura del socio por encima de su aportación económica: la condición de socio puede transmitirse intervivos o por herencia sólo en el caso de que el sustituto reúna cualidades similares a las de aquél y, además, la Asamblea General lo apruebe (Román-Cervantes, 2008).

El no cumplimiento estricto por parte de estas entidades de ciertos principios cooperativos (CIRIEC, 1995), ha dado lugar a cierto debate académico en torno a su consideración como entidades de Economía Social (Bel Durán, 1995; Román-Cervantes, 2008; Vargas-Vasserot, 2009), y que la Ley 5/2011 ha venido a cerrar con el reconocimiento expreso como agentes del Tercer Sector.

Esta revisión de la literatura permite identificar como objetivo principal de investigación en este estudio el establecimiento de indicadores específicos que permitan monitorizar la contribución a la dimensión social de la sostenibilidad de las SATs, una familia de entidades del Tercer Sector para la cual, hasta el momento, no se disponen de métricas de desempeño social. Este trabajo se suma a la línea de investigación empírica reciente basado en el desarrollo de sistemas de medición e indicadores para cuantificar el impacto socioeconómico de las organizaciones de economía social (Bassi y Vincenti, 2015; Etxezarreta et al., 2018; Monzón et al., 2013; Retolaza et al., 2015).

\section{Las SATs en Canarias. La contabilidad social}

\subsection{Contexto geográfico y población}

El ámbito geográfico de este estudio es el archipiélago canario, una de las Comunidades Autónomas del Reino de España y región ultraperiférica de la Unión Europea, situada frente a la costa noroeste del continente africano -a $4^{\circ}$ del Trópico de Cáncer, aproximadamente-. De origen volcánico, cuenta con 8 islas principales, 3 islotes y 2 rocas, $7.447 \mathrm{~km}^{2}$ de superficie y $1.379 \mathrm{~km}$ de longitud de litoral (Instituto Canario de Estadística, 2019). Sus condiciones térmicas son suaves, con escasos contrastes estacionales a lo largo del $a_{n ̃ o}{ }^{26}$. Su clima, en general, es subtropical seco y húmedo, si bien presenta microclimas, o diferencias climatológicas acentuadas en cortas distancias, que propician una gran diversidad ecológica y contrastes paisajísticos ${ }^{27}$. Estas características han conformado a este conjunto insular como un importante destino

20 Este elemento favorece la creación de SATs frente a cooperativas, por requerirse en éstas al menos 7 socios para su constitución (Bel Durán, 1995; Román Cervantes, 2008).

21 Se inscriben en el Registro General de las SAT, dependiente del Ministerio de Agricultura, Pesca y Alimentación, aquellas sociedades agrarias de ámbito nacional. Desde 1992, las SATs que operan a escala regional se inscriben en los Registros de las Comunidades Autónomas. El domicilio fiscal es el factor que, en la práctica, determina la inscripción en uno u otro registro (Bel Durán, 1995; Román-Cervantes, 2008; Vargas-Vasserot, 2009).

22 En otras palabras, los socios con mayor poder económico son los que establecen las estrategias de inversiones, comercialización o fusión con otras entidades (Román-Cervantes, 2008).

23 Bel Durán (1995), siguiendo a García-Gutiérrez (1991), considera a las SATs sociedades participativas, por corresponder a los socios la fijación de objetivos y por estar presentes en los procesos de producción, comercialización y financieros.

24 No se cumple en estas entidades el principio cooperativo de participación económica de los socios (CIRIEC, 1995).

25 Esta característica supone el incumplimiento del principio cooperativo de exclusividad (Román-Cervantes, 2008b).

26 A título ilustrativo, en 2016 la temperatura media anual fue de $22^{\circ}$, y el rango térmico medio mensual de $8,2^{\circ}$ (Instituto Nacional de Estadística, 2019).

27 El archipiélago posee 4 parques nacionales, 11 parques naturales, y un total de un total de 146 espacios naturales protegidos, con una extensión de 301.237 ha. (Instituto Canario de Estadística, 2019). 
turístico internacional, habiendo recibido en 2018 a más de 13 millones de viajeros internacionales ${ }^{28}$ (Instituto Nacional de Estadística).

Las actividades características del turismo son el principal motor de la economía regional, suponiendo el 34,3\% de la producción de 2016 (Instituto Canario de Estadística). Por su parte, el peso de la agricultura en la estructura económico-productiva del archipiélago se ha reducido de forma sistemática en los últimos años: en el período 2009-2017, la proporción de la producción agrícola en el PIB regional ha descendido en dos décimas porcentuales (de 1,47\% a 1,26\%), y la del empleo agrícola en el total, en 1,5 décimas porcentuales (de 2,75\% a 2,59\%) (Instituto Canario de Estadística).

Asimismo, cuando se comparan los datos de 1999 y 2009 referidos a densidad de población y superficie cultivada de los 88 municipios del archipiélago (Instituto Canario de Estadística), se desprenden dos dinámicas que, en cierta medida, podrían considerarse preocupantes. En primer lugar, en 24 comarcas con tradición agrícola, y próximas a puntos turísticos, se ha reducido la extensión de tierras labradas y aumentado la concentración de población ${ }^{29}$. El segundo hecho es que, en 7 municipios rurales, alejados de puntos turísticos y de ciudades capitalinas, se ha dejado de cultivar superficie agrícola y han perdido población ${ }^{30}$.

Los propietarios de las explotaciones agrarias, trabajadores agrícolas o personas jurídicas con fines agrarios se asocian en Canarias utilizando, entre otras, la fórmula de las Sociedades Agrarias de Transformación. En 2018 hay registradas 440 de estas entidades, el 3,6 \% de las existentes en España (Ministerio de Agricultura, Pesca y Alimentación, 2019). Los agricultores y ganaderos del archipiélago utilizan esta forma de asociacionismo en mayor medida que la cooperativa: de las entidades de economía social en el sector agrario, el 79\% son SAT y, el 21\% restante, cooperativas agrarias (Cátedra Cajasiete de Economía Social y Cooperativa de la Universidad de La Laguna, 2019).

\subsection{Caso de estudio}

Tras haber realizado un filtrado de las SATs de Canarias, y mantenido entrevistas previas para comprobar su disponibilidad, se ha tomado como caso de estudio una de ellas, emplazada en la vertiente septentrional de la isla de Tenerife. Se trata de una entidad que tiene una cierta tradición en el desarrollo de acciones de carácter social y medioambiental, iniciando recientemente la rendición de cuentas a la ciudadanía conforme a marcos de referencia habituales. Su responsabilidad con las consecuencias derivadas de su actividad va más allá de la internalización de los impactos negativos, tratando de promover, a través de sus actuaciones, la generación de valor para la sociedad. Para la gestión efectiva de esta orientación hacia la sostenibilidad, la organización precisa de métricas que lo permitan y de las que, en la actualidad, carece. Todos estos elementos conforman a esta SAT como una entidad idónea para llevar a cabo este estudio.

Originariamente constituida en 1914 como sindicato agrícola, su objeto social es la comercialización de los productos agrarios. Componen su censo un total de 229 socios, personas físicas y jurídicas productores de frutas y hortalizas. La entidad facilita la comercialización y distribución de la producción agrícola que obtienen, y la recolección y transporte hasta sus dependencias. Se trata de una sociedad agraria de tamaño mediano, integrada por 112 trabajadores en media anual. Las prácticas de recursos humanos de la organización tratan de impulsar un empleo de calidad, promover la diversidad, la igualdad y la conciliación de su vida laboral, familiar y personal, contribuir a la formación continua y al desarrollo personal en igualdad de oportunidades, y cuidar de la salud y seguridad de los trabajadores. Por su parte, la política de compras se caracteriza por la elección preferente de organizaciones de ámbito regional y con gestión empresarial responsable.

La SAT de estudio posee certificaciones en seguridad alimentaria, ISO 22.000 , y en gestión medioambiental, ISO 14001, colabora de manera frecuente y fluida con medios de comunicación tradicionales y redes sociales on-line. Asimismo, apoya a entidades de naturaleza pública y del tercer sector para el desarrollo de causas sociales, educativas, o valores alineados con la sostenibilidad.

\subsection{La Contabilidad Social}

En este trabajo se utiliza el modelo de la Contabilidad Social (Retolaza et al., 2016) como marco para establecer un conjunto de indicadores específicos que permitan evaluar y monitorizar la contribución a la sostenibilidad social de la SAT de estudio. Se trata de un sistema de información que complementa y amplía al de la contabilidad tradicional en una doble dimensión, tanto en cuanto a la naturaleza del valor considerado como a los grupos de interés contemplados, permitiendo objetivar en una única medida

\footnotetext{
28 En concreto, a 13.751.914 turistas internacionales, según datos de la Encuesta de Movimientos Turísticos en Frontera (INE).

29 Son los municipios de San Bartolomé, Ingenio, La Aldea de San Nicolás, Vega de San Mateo, Adeje, Arico, Fasnia, Granadilla, Guía de Isora, La Laguna, La Matanza de Acentejo, Puerto de la Cruz, El Rosario, San Miguel de Abona, Santa Cruz de Tenerife, Santiago del Teide, Tacoronte, Tegueste, La Victoria de Acentejo, Vilaflor, Alajeró, El Pinal de El Hierro, Breña Alta, Tijaraje y Villa de Mazo.

30 Municipios de Artenara, Moya, Valleseco, Frontera, Garafía, San Andrés y Sauces, y Tazacorte.
} 
monetaria el valor económico y social atribuible a la gestión, el valor social integrado o blended value (Emerson y Bonini, 2003), y satisfacer las demandas de información de los stakeholders (Freeman, 1984).

En el ámbito de la economía social, este sistema de información contable ha sido empleado para plantear métricas específicas que posibiliten cuantificar el impacto socio-económico generado por diversas familias de entidades de naturaleza social, como cooperativas (Etxezarreta et al., 2018), fundaciones (Retolaza et al., 2015), u organizaciones sin ánimo de lucro (Retolaza y San-José, 2016), no habiéndose aplicado aún a las SATs.

La Contabilidad Social (Retolaza et al., 2016) se desarrolla sobre la base de un análisis coste-beneficio (Mishan, 2007) y las cuatro hipótesis metodológicas siguientes: (a) un proceso de investigación participativo de action research (Lewin, 1946), caracterizado por la combinación de teoría y práctica; (b) una aproximación al concepto del valor social desde la teoría de los stakeholders (Freeman, 1984), que permite concretar el valor social de una entidad al que la misma genera a sus grupos de interés ${ }^{31}$; (c) el paradigma fenomenológico (Tarde, 1902; Polkinghorne, 1989; Husserl, 1990), que conlleva un acercamiento al valor social desde una óptica subjetiva ${ }^{32}$; y la hipótesis de la lógica difusa (Zadeh, 1965; Kaufmann \& Gil Aluja, 1986), que permite monetizar el valor social haciendo uso de instrumentos propios de los sistemas de conjuntos borrosos.

El modelo de análisis del valor social que resulta de la unificación de los elementos anteriores, denominado modelo poliédrico o Social Value Polyhedral Model (SPOLY) (Retolaza et al., 2016), es un modelo analítico-sintético cuya representación gráfica podría considerarse semejante a una flor (Figura 3): el círculo interior recoge el valor social que la organización genera y es reconocido como tal por sus grupos de interés, y los pétalos, el valor identificado por un determinado grupo de interés y que no confluye con el resto.

El blended value está integrado en este modelo por tres componentes, el valor socio - económico o valor social de mercado, el valor social específico o de no mercado, y el valor emocional. El primero de ellos hace referencia al valor social que la organización genera con la realización de su actividad económica, siendo transferido como contrapartida de un precio real de mercado (y recogido en la contabilidad de la organización). Este valor social de mercado es conceptualizado desde una perspectiva amplia, conformado, por una parte, por el valor añadido que de forma directa una organización genera y distribuye, obtenido siguiendo el procedimiento del Estado de Valor Añadido, EVA (Gonzalo y Pérez, 2017:37-38) y, por otra, por el valor que, de forma indirecta, genera con las compras de insumos (Retolaza et al., 2015). Las métricas que se establecen para determinar este componente del valor social están referidas a los outcomes, tanto directos como indirectos, siendo comunes para el conjunto de organizaciones, de cualquier su naturaleza ${ }^{33}$.

Figura. 3. Modelo Poliédrico de Análisis del Valor Social.

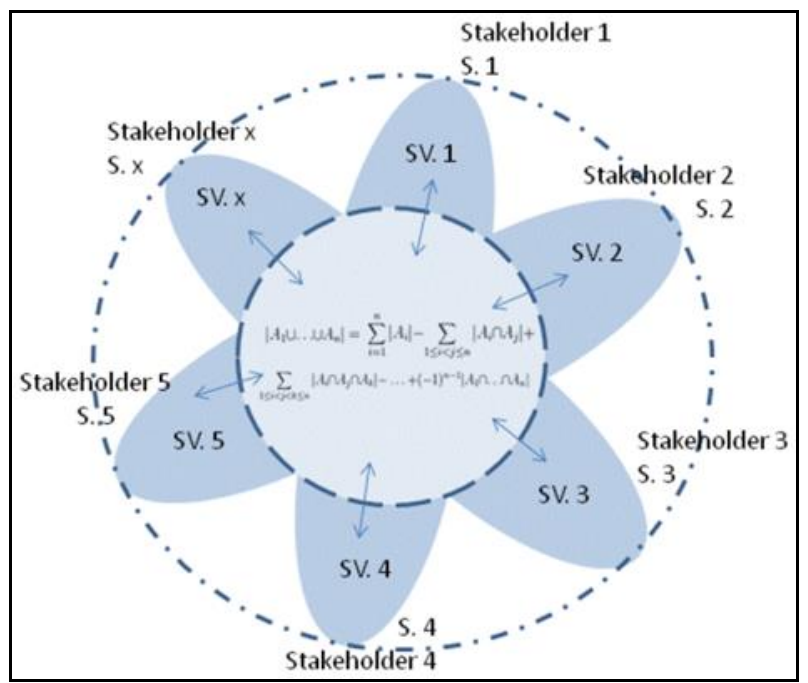

Fuente: Retolaza et al. (2016).

31 Quienes participan y resultan afectados por la actividad de la organización.

32 Se considera únicamente el valor que, como tal, es percibido por los stakeholders de una organización. Por tanto, bajo este planteamiento, el valor social es específico para una entidad en un momento concreto del tiempo.

33 Asimismo, se consideran aquí los inputs cuya utilización tuviese un coste de oportunidad directo y que pudiesen utilizarse de forma alternativa para generar valor social. 
El segundo de los componentes del blended value, el valor social específico o de no mercado, es concebido como el valor transferido por la organización a sus grupos de interés, sin contrapartida de precio real de mercado. Para su cuantificación han de darse una serie de pasos, que podrían sintetizarse como sigue. En primer lugar, es necesario identificar a los stakeholders de la organización, consensuarlos con la dirección, y representarlos en un mapa. En una segunda fase, se realizan entrevistas en profundidad a los representantes de los distintos grupos o colectivos, con el objeto de determinar sus intereses y especificar las denominadas variables de valor, o expresiones cualitativas del valor percibido. Posteriormente, se establecen indicadores para la cuantificación de los outputs y outcomes generados por la organización, y percibidos como valor por sus grupos de interés, así como proxys, o aproximaciones financieras, que permitirían, mediante un proceso similar al que se utiliza en contabilidad para calcular el valor razonable, monetizar tales outputs y outcomes.

El tercer y último componente del valor social integrado, el valor emocional, recoge la satisfacción que una entidad genera a sus grupos de interés. Este ecosistema de valor social es cuantificado a través de un cuestionario, diseñado conforme a la escala SERVQUAL sobre calidad del servicio (Parasuraman, Zeithaml \& Berry 1988, 1991), al que los interlocutores de los distintos colectivos dan respuesta (Ruiz-Roqueñi, 2018).

La Contabilidad Social constituye un sistema de medición del valor social especialmente apropiado para este estudio, dado el objetivo principal planteado, el diseño de métricas de sostenibilidad social específicas para las SATs. La aproximación subjetiva para la objetivación del valor social en que se basa, al estar conceptualmente alineada con la filosofía de la sostenibilidad (World Commission on Environment and Development, 1987), permite la identificación de los stakeholders, el posterior análisis de sus intereses y percepciones, y el planteamiento de indicadores de sostenibilidad social particulares para la organización ${ }^{34}$. Concretamente, posibilita el diseño de indicadores y aproximaciones financieras del valor social generado por la entidad, y percibido por sus grupos de interés, para la monitorización del valor social específico, referidas a outputs y outcomes percibidos como valor por los stakeholders de la organización en un momento concreto del tiempo.

\section{Resultados}

En este apartado se exponen los hallazgos encontrados en cada una de las fases del proceso estandarizado que, en el sistema de Contabilidad Social, debe seguirse para el establecimiento de indicadores y proxys del valor social específico de la SAT objeto de estudio. Tales métricas permitirán, en última instancia, la evaluación y seguimiento de la contribución a la sostenibilidad social de la entidad.

\subsection{Identificación de los stakeholders}

El análisis de los documentos estratégicos de la organización y las reuniones con su equipo directivo, han posibilitado delimitar a los grupos de interés de la entidad. Tales colectivos se han representado en el mapa de stakeholders de la Figura 4, siendo descritos en la Tabla 3.

Tabla. 3. Descripción de los stakeholders de la SAT.

\begin{tabular}{l|l}
\hline Stakeholders & Descripción \\
\hline \hline Asociados & $\begin{array}{l}\text { Los socios de la entidad son productores de plátano, otras frutas y hortalizas. De ellos, un } \\
60 \%, \text { aproximadamente, son de pequeño y mediano tamaño. }\end{array}$ \\
\hline $\begin{array}{l}\text { Equipo humano } \\
\text { Proveedores } \\
\text { acreedores }\end{array}$ & $\begin{array}{l}\text { Grupo integrado por la Junta Rectora de la entidad, el equipo directivo y los trabajadores, } \\
\text { con actividad laboral en las plantas de empaquetado y las oficinas. }\end{array}$ \\
\hline $\begin{array}{l}\text { económico-productiva a la SAT. } \\
\text { Se ha distinguido a las que proporcionan suministros y aprovisionamientos, servicios y, } \\
\text { por último, las que abastecen de otras frutas y hortalizas para la venta al cliente. }\end{array}$ \\
$\begin{array}{l}\text { Entidades contratadas por la SAT para la prestación de los servicios de recogida de } \\
\text { plátano en las fincas de los socios, transporte de fruta y hortalizas, limpieza de las naves } \\
\text { de producción, montaje de las cajas de fruta en las plantas de empaquetado, y selección de }\end{array}$ \\
\hline
\end{tabular}

34 En otros ámbitos, como el del turismo, se lleva a cabo también la medición de la sostenibilidad a través de una aproximación fenomenológica identificación de los stakeholders del destino turístico y posterior análisis de sus valores, percepciones e intereses (Poudel et al., 2016; Randle y Hoye, 2016)-. 


\begin{tabular}{l|l}
\hline & los plátanos sueltos o dedos. \\
\hline Clientes & $\begin{array}{l}\text { Grandes superficies y pequeños comercios minoristas a los que la SAT vende las frutas y } \\
\text { hortalizas adquiridas, a sus asociados o a otras entidades, tras su empaquetado. }\end{array}$ \\
\hline Ganaderos & $\begin{array}{l}\text { La SAT deposita la fruta sobrante, e inservible para el consumo humano, en } \\
\text { emplazamientos a los que tienen acceso los propietarios de ganado, para su libre } \\
\text { disposición como alimento para sus animales. }\end{array}$ \\
\hline $\begin{array}{l}\text { Entidades de } \\
\text { certificación } \\
\text { apoyo }\end{array} \quad \begin{array}{l}\text { Entidades especializadas que facilitan la revisión y actualización de los sistemas de } \\
\text { gestión y de trabajo implantados en la SAT, ISO 22.000 e ISO 14001. }\end{array}$ \\
$\begin{array}{l}\text { Medios } \\
\text { comunicación }\end{array}$ & $\begin{array}{l}\text { Prensa, radio y televisión locales, con los que la SAT colabora de manera frecuente y } \\
\text { fluida. Integra también las redes sociales virtuales, Facebook, Twitter, Instagram, } \\
\text { LinkedIn y YouTube, en las que se informa diariamente de las actividades y estado de } \\
\text { situación de los proyectos que se desarrollan. }\end{array}$ \\
\hline $\begin{array}{l}\text { Sociedad } \\
\text { Entidades de naturaleza pública y del tercer sector con las que la SAT coopera de manera } \\
\text { intensa, apoyando las causas sociales de la Administración Pública, centros educativos, } \\
\text { entidades del Tercer Sector de Acción Social, Centros y Asociaciones Deportivas, } \\
\text { Asociaciones Profesionales y Asociaciones Sin Ánimo de Lucro. }\end{array}$ \\
\hline $\begin{array}{l}\text { Consumidores a los que la entidad enfoca todas sus operaciones, para satisfacer y superar } \\
\text { sus expectativas. No tiene trato directo con ellos. }\end{array}$ \\
\hline
\end{tabular}

Fuente: Elaboración propia.

\subsection{Análisis de los intereses de los stakeholders}

El análisis de los intereses de los diferentes grupos de interés se ha realizado mediante 36 entrevistas en profundidad a los representantes de los distintos colectivos prioritarios, según el listado propuesto por el equipo directivo de la SAT de estudio. La información cualitativa recogida ha permitido identificar 18 variables de valor, o dimensiones de valor percibido (Tabla 4), que muestran el valor percibido por los stakeholders y atribuido a determinados outputs o outcomes derivados de la actuación de la SAT.

La descripción de variables de valor e intereses de los distintos colectivos se sintetiza en la matriz de intereses de la Tabla 5. Dicha matriz permite visualizar la relación entre los intereses identificados por cada uno de los stakeholders. 
Figura. 4. Mapa de stakeholders de la SAT.

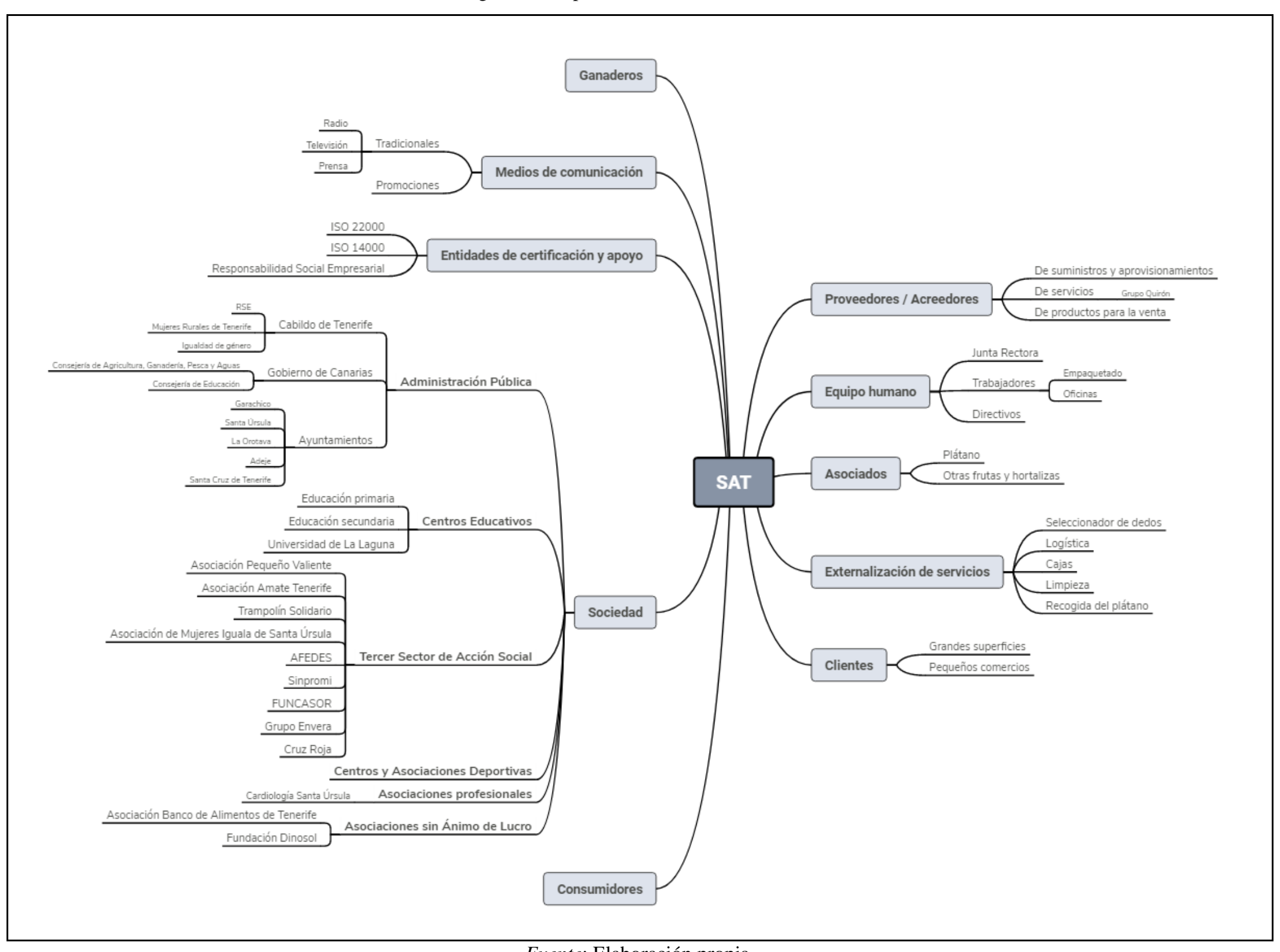

Fuente: Elaboración propia. 
Tabla. 4. Descripción de las variables de valor.

\begin{tabular}{|c|c|}
\hline Stakeholders & \\
\hline Respuesta social & $\begin{array}{l}\text { La aportación continuada y permanente de recursos tangibles e intangibles por parte de } \\
\text { la SAT a los agentes del tercer sector de acción social y sin ánimo de lucro, } \\
\text { Administraciones Públicas, centros educativos, asociaciones deportivas, y asociaciones } \\
\text { profesionales, permite y facilita que estas organizaciones lleven a cabo su misión. }\end{array}$ \\
\hline Divulgación & $\begin{array}{l}\text { Los organismos de la Administración Pública, asociaciones profesionales y entidades } \\
\text { del tercer sector de acción social valoran la participación de la SAT en sus iniciativas y } \\
\text { proyectos, ya que logran que éstos tengan una mayor difusión y repercusión social. }\end{array}$ \\
\hline Asesoramiento & $\begin{array}{l}\text { Los agentes de inserción del tercer sector de acción social y los asociados valoran la } \\
\text { orientación desinteresada proporcionada por la SAT, bien de aspectos laborales o } \\
\text { asesoramiento técnico-agrícola, respectivamente. }\end{array}$ \\
\hline Empleabilidad & $\begin{array}{l}\text { Las entidades del tercer sector de acción social y organismos de la Administración } \\
\text { Pública obtienen utilidades de la contribución realizada por la SAT a la inserción } \\
\text { laboral de personas con discapacidades. }\end{array}$ \\
\hline $\begin{array}{l}\text { Seguridad } \\
\text { económica }\end{array}$ & $\begin{array}{l}\text { La organización proporciona certidumbre económica a los diferentes colectivos con los } \\
\text { que se relaciona: trabajadores, a través del empleo de calidad y la promoción interna; } \\
\text { asociados, asegurando la recogida y venta de la producción agrícola a buen precio; y } \\
\text { entidades del tercer sector de acción social y centros educativos, atendiendo a las } \\
\text { necesidades que le planteen. }\end{array}$ \\
\hline $\begin{array}{l}\text { Ampliación de } \\
\text { oportunidades } \\
\text { económicas }\end{array}$ & $\begin{array}{l}\text { Las entidades del tercer sector de acción social valoran las actividades de la SAT que } \\
\text { hacen posible que familias con menor poder adquisitivo puedan acceder al consumo de } \\
\text { un alimento sano. }\end{array}$ \\
\hline Sostenibilidad & $\begin{array}{l}\text { Los clientes, centros educativos, entidades del tercer sector de acción social, centros } \\
\text { deportivos y asociaciones profesionales valoran el efecto positivo de las acciones de la } \\
\text { entidad en las diferentes dimensiones de la sostenibilidad. }\end{array}$ \\
\hline $\begin{array}{lr}\text { Reputación } & y \\
\text { ampliación } & \text { del } \\
\text { mercado } & \end{array}$ & $\begin{array}{l}\text { Los proveedores y entidades de externalización de servicios se benefician de tener a la } \\
\text { SAT en su cartera de clientes, al mejorar su imagen y facilitar el establecimiento de } \\
\text { relaciones comerciales con otros agentes. }\end{array}$ \\
\hline $\begin{array}{l}\text { Fomento de redes } \\
\text { informales y de } \\
\text { colaboración }\end{array}$ & $\begin{array}{l}\text { Los proveedores y acreedores, las entidades de externalización de servicios y los } \\
\text { trabajadores valoran las acciones llevadas a cabo por la SAT que favorecen la } \\
\text { aparición de redes informales entre ellos. }\end{array}$ \\
\hline $\begin{array}{l}\text { Confianza y fluidez } \\
\text { de comunicación }\end{array}$ & $\begin{array}{l}\text { La agilidad, la cooperación y la cercanía de trato que caracterizan a la SAT es valorada } \\
\text { por los organismos de la Administración Pública, los proveedores y acreedores, } \\
\text { entidades de externalización de servicios, del tercer sector de acción social y los } \\
\text { trabajadores. }\end{array}$ \\
\hline $\begin{array}{l}\text { Reconocimiento del } \\
\text { trabajo }\end{array}$ & $\begin{array}{l}\text { o humano de la SAT valora que la dirección de la entidad muestre una } \\
\text { n por el trabajo bien hecho. }\end{array}$ \\
\hline Formación & ajadores valoran las acciones de desarrollo formativo y profesional. \\
\hline Flexibilidad & $\begin{array}{l}\text { aipo humano valora que la entidad haga posible la conciliación de la vida } \\
\text { ar, personal y profesional. }\end{array}$ \\
\hline Poder de decisión & oner de cierta autonomía en la toma de decisiones. \\
\hline Igualdad de género & $\begin{array}{l}\text { Los organismos de la Administración Pública valoran el compromiso e implicación de } \\
\text { la SAT en el impulso de la equiparación de género, tanto en su propia plantilla como } \\
\text { en la sociedad canaria }\end{array}$ \\
\hline $\begin{array}{l}\text { Espíritu } \\
\text { cooperativo } \quad y \\
\text { solidaridad interna }\end{array}$ & $\begin{array}{l}\text { Los socios, trabajadores, centros y asociaciones deportivas y entidades del tercer sector } \\
\text { de acción social valoran que los principios de comportamiento de la SAT sean el } \\
\text { equilibrio distributivo, la priorización de los valores sociales y el cooperativismo. }\end{array}$ \\
\hline $\begin{array}{l}\text { Elección ética de } \\
\text { proveedores }\end{array}$ & $\begin{array}{l}\text { Los proveedores y acreedores y entidades de externalización de servicios reconocen } \\
\text { que la respuesta social, característica de la actuación de ambas partes, incide } \\
\text { positivamente en la confianza mutua. }\end{array}$ \\
\hline $\begin{array}{l}\text { Proactividad } \\
\text { innovación }\end{array}$ & $\begin{array}{l}\text { El emprendimiento y la mejora continua de la SAT son aspectos valorados por los } \\
\text { clientes, entidades del tercer sector de acción social y centros y asociaciones } \\
\text { deportivas. }\end{array}$ \\
\hline
\end{tabular}

Fuente: Elaboración propia. 
Tabla. 5. Matriz de intereses de los stakeholders.

\begin{tabular}{|c|c|c|c|c|c|c|c|c|c|c|c|c|c|c|c|}
\hline \multirow{2}{*}{ Variables de valor } & \multicolumn{15}{|c|}{ Stakeholders (*) } \\
\hline & $\mathrm{CL}$ & EH & AS & EX & PA & $\mathrm{MC}$ & $\mathrm{CA}$ & AP & $\mathrm{CE}$ & TS & $\mathrm{CD}$ & PR & SL & $\mathrm{CO}$ & GN \\
\hline Respuesta social & & & & & & & & $\checkmark$ & $\bar{v}$ & $\bar{s}$ & 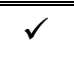 & 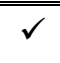 & $\bar{c}$ & & \\
\hline Divulgación & & & & & & & & $\checkmark$ & & $\checkmark$ & & $\checkmark$ & & & \\
\hline Asesoramiento & & & $\checkmark$ & & & & & & & $\checkmark$ & & & & & \\
\hline Empleabilidad & & & & & & & & $\checkmark$ & & $\checkmark$ & & & & & \\
\hline Seguridad económica & $\checkmark$ & $\checkmark$ & & & & & & $\checkmark$ & $\checkmark$ & $\checkmark$ & & & & & \\
\hline $\begin{array}{l}\text { Ampliación } \\
\text { oportunidades } \\
\text { económicas }\end{array}$ & & & & & & & & & & $\checkmark$ & & & & & \\
\hline Sostenibilidad & $\checkmark$ & & & & & & & & $\checkmark$ & $\checkmark$ & $\checkmark$ & $\checkmark$ & & & $\checkmark$ \\
\hline $\begin{array}{lr}\text { Reputación } & y \\
\text { ampliación del mercado }\end{array}$ & & & $\checkmark$ & $\checkmark$ & $\checkmark$ & & & & & & & & & & \\
\hline $\begin{array}{l}\text { Fomento de redes } \\
\text { informales internas y } \\
\text { externas }\end{array}$ & & $\checkmark$ & & $\checkmark$ & $\checkmark$ & & & & & & & & & & \\
\hline $\begin{array}{l}\text { Confianza y fluidez de } \\
\text { comunicación }\end{array}$ & & $\checkmark$ & & $\checkmark$ & $\checkmark$ & & & $\checkmark$ & & $\checkmark$ & & & & & \\
\hline $\begin{array}{l}\text { Reconocimiento del } \\
\text { trabajo }\end{array}$ & & $\checkmark$ & & & & & & & & & & & & & \\
\hline Formación & & $\checkmark$ & & & & & & & & & & & & & \\
\hline Flexibilidad & & $\checkmark$ & & & & & & & & & & & & & \\
\hline Poder de decisión & & $\checkmark$ & & & & & & & & & & & & & \\
\hline Igualdad de género & & & & & & & & $\checkmark$ & & & & & & & \\
\hline $\begin{array}{l}\text { Espiritu cooperativo y } \\
\text { solidaridad interna }\end{array}$ & & $\checkmark$ & $\checkmark$ & & & & & & & $\checkmark$ & $\checkmark$ & & & & \\
\hline $\begin{array}{l}\text { Elección ética de } \\
\text { proveedores }\end{array}$ & & & $\checkmark$ & $\checkmark$ & & & & & & & & & & & \\
\hline $\begin{array}{l}\text { Proactividad } \quad e \\
\text { innovación }\end{array}$ & $\checkmark$ & & & & & & & & & $\checkmark$ & $\checkmark$ & $\checkmark$ & & & \\
\hline
\end{tabular}

(*) CL: Clientes - EH: Equipo humano - AS: Asociados - EX: Externalización de Servicios - PA: Proveedores/Acreedores - MC: Medios de Comunicación - CA: Entidades de Certificación y Apoyo - AP: Administración Pública - CE: Centros Educativos - TS: Tercer Sector de Acción Social - CD: Centros y Asociaciones Deportivas - PR: Asociaciones Profesionales - SL: Asociaciones Sin Ánimo de Lucro - CO: Consumidores - GN: Ganaderos.

Fuente: Elaboración propia.

\subsection{Establecimiento de métricas del valor social específico}

Teniendo presente la descripción de las variables de valor (Tabla 4), se proponen como indicadores para la cuantificación de los outputs generados y percibidos como valor los recogidos de la Tabla 6. Por su parte, las aproximaciones financieras o proxys que permiten monetizar dichos indicadores-identificadas mediante un proceso similar al que se utiliza en contabilidad para calcular el valor razonable- se muestran también en dicha tabla, así como los algoritmos de cálculo que relacionan los outputs con los proxys -a fin de cuantificar el valor monetario de cada outcome generado-. 
Tabla. 6. Indicadores, proxys y algoritmos de cálculo.

\begin{tabular}{|c|c|c|c|}
\hline $\begin{array}{l}\text { Variable } \\
\text { de valor }\end{array}$ & Indicador & Proxy & Algoritmo \\
\hline \multirow[t]{19}{*}{ Respuesta social } & Kg plátanos & Precio kg plátano & Kg plátanos * Precio kg plátanos \\
\hline & $\mathrm{N}^{\mathrm{o}}$ piñas de plátanos & Precio piña plátano & $\mathrm{N}^{\mathrm{o}}$ piñas plátanos $*$ Precio piña plátano \\
\hline & $\mathrm{Kg}$ frutas varias & Precio kg fruta & $\mathrm{Kg}$ frutas varias $*$ Precio $\mathrm{kg}$ fruta \\
\hline & $\mathrm{Kg}$ naranjas & Precio kg naranja & $\mathrm{Kg}$ naranjas * Precio kg naranja \\
\hline & Kg papayas & Precio kg papaya & Kg papayas $*$ Precio kg papaya \\
\hline & Kg hortalizas & Precio kg hortaliza & Kg hortalizas * Precio kg hortaliza \\
\hline & Material escolar & $\begin{array}{l}\text { Precio material } \\
\text { escolar }\end{array}$ & Material escolar * Precio material escolar \\
\hline & Recursos financieros & Importe monetario & Importe monetario \\
\hline & Juguetes donados & $\begin{array}{l}\text { Precio mercado } \\
\text { segunda mano }\end{array}$ & Juguetes* Precio mercado segunda mano \\
\hline & $\begin{array}{l}\text { Material infantil } \\
\text { donado }\end{array}$ & $\begin{array}{l}\text { Precio mercado } \\
\text { segunda mano }\end{array}$ & $\begin{array}{l}\text { Material infantil * Precio mercado segunda } \\
\text { mano }\end{array}$ \\
\hline & $\mathrm{Kg}$ fruta variada & Precio $\mathrm{kg}$ fruta & $\mathrm{Kg}$ fruta variada $*$ Precio $\mathrm{kg}$ fruta \\
\hline & $\mathrm{N}^{\mathrm{o}} \mathrm{h}$. charla formativa & Salario/h. docente & $\mathrm{N}^{\mathrm{o}} \mathrm{h}$. charla formativa $*$ Salario/h. docente \\
\hline & $\mathrm{N}^{\circ}$ h. personal apoyo & $\begin{array}{l}\text { Salario/h. azafato } \\
\text { congresos }\end{array}$ & $\begin{array}{l}\mathrm{N}^{\mathrm{o}} \text { h. personal apoyo } * \text { Salario/h. azafato } \\
\text { congresos }\end{array}$ \\
\hline & $\mathrm{N}^{\circ}$ h. curso formación & Salario/h. docente & $\mathrm{N}^{\mathrm{o}}$ h. curso formación * Salario/h. docente \\
\hline & $\mathrm{N}^{\mathrm{o}}$ h. curso formación & Salario/h. docente & $\mathrm{N}^{\mathrm{o}}$ h. curso formación $*$ Salario/h. docente \\
\hline & Recursos financieros & $\begin{array}{l}\text { Importe monetario } \\
\text { recibido }\end{array}$ & Importe monetario recibido \\
\hline & $\mathrm{N}^{\mathrm{o}}$ h. curso formación & Salario/h. docente & $\mathrm{N}^{\mathrm{o}}$ h. curso formación $*$ Salario/h. docente \\
\hline & $\begin{array}{l}\mathrm{N}^{\circ} \quad \mathrm{h} . \\
\text { exposiciones }\end{array}$ & $\begin{array}{l}\text { Salario/h director } \\
\text { comercio } \\
\text { alimentación }\end{array}$ & $\begin{array}{l}\mathrm{N}^{\circ} \text { h. trabajo exposiciones } * \text { Salario } / \mathrm{h} \\
\text { director comercio alimentación }\end{array}$ \\
\hline & $\mathrm{Kg}$ fruta variada & $\begin{array}{lll}\text { Precio } & \mathrm{kg} & \text { fruta } \\
\text { variada } & & \\
\end{array}$ & $\mathrm{Kg}$ fruta variada $*$ Precio $\mathrm{kg}$ fruta \\
\hline Divulgación & $\mathrm{N}^{\mathrm{o}}$ actos & $\begin{array}{lr}\text { Precio } & \text { anuncio } \\
\text { patrocinado } & \text { en } \\
\text { Facebook } & \\
\end{array}$ & $\begin{array}{l}\mathrm{N}^{\circ} \text { actos } * \text { Precio anuncio patrocinado en } \\
\text { Facebook }\end{array}$ \\
\hline Asesoramiento & Asesoramiento laboral & $\begin{array}{l}\text { Cuota anual de } \\
\text { asesoría laboral }\end{array}$ & Cuota anual de asesoría laboral \\
\hline & $\begin{array}{l}\text { Asesoramiento técnico- } \\
\text { agrícola }\end{array}$ & $\begin{array}{l}\text { Salario bruto anual } \\
\text { técnico-agrícola }\end{array}$ & Salario bruto anual técnico-agrícola \\
\hline $\begin{array}{l}\text { Variable } \\
\text { de valor }\end{array}$ & Indicador & Proxy & Algoritmo \\
\hline Empleabilidad & $\begin{array}{l}\mathbf{N}^{\mathbf{0}} \text { trabajadores } \\
\text { insertados }\end{array}$ & Subvención recibida & Subvención recibida \\
\hline & $\begin{array}{l}\mathrm{N}^{\mathrm{o}} \text { horas prácticas } \\
\text { formativas }\end{array}$ & $€ /$ h Curso FGULL & $\begin{array}{l}\mathrm{N}^{\circ} \text { horas prácticas formativa* } € / \mathrm{h} \text { Curso } \\
\text { FGULL }\end{array}$ \\
\hline $\begin{array}{l}\text { Seguridad } \\
\text { económica }\end{array}$ & $\begin{array}{l}\mathrm{N}^{\mathrm{o}} \text { trabajadores } \\
\text { insertados }\end{array}$ & $\begin{array}{l}\text { Salario anual trabajador } \\
* \text { Tipo de interés medio } \\
\text { crédito al consumo a } \\
\text { corto plazo }\end{array}$ & $\begin{array}{l}\mathrm{N}^{\mathrm{o}} \text { trabajadores insertados } * \text { Salario anual } \\
\text { trabajador } * \text { Tipo de interés medio crédito al } \\
\text { consumo a corto plazo }\end{array}$ \\
\hline & $\begin{array}{l}\mathrm{N}^{\circ} \quad \text { trabajadores } \\
\text { temporales }\end{array}$ & $\begin{array}{l}\text { Salario anual trabajador } \\
* \text { Tipo de interés medio } \\
\text { crédito al consumo a } \\
\text { corto plazo }\end{array}$ & $\begin{array}{l}N^{o} \text { trabajadores temporales } * \text { Salario anual } \\
\text { trabajador } * \text { Tipo de interés medio crédito al } \\
\text { consumo a corto plazo }\end{array}$ \\
\hline & $\mathrm{N}^{\mathrm{o}}$ trabajadores fijos & $\begin{array}{l}\text { Diferencial salario anual } \\
\text { respecto Coplaca * Tipo } \\
\text { de interés medio crédito } \\
\text { al consumo a corto plazo }\end{array}$ & $\begin{array}{l}\mathrm{N}^{\mathrm{o}} \text { trabajadores fijos } * \text { Diferencial salario } \\
\text { anual respecto Coplaca } * \text { Tipo de interés } \\
\text { medio crédito al consumo a corto plazo }\end{array}$ \\
\hline & $\mathrm{N}^{\mathrm{o}}$ socios pequeños - & Precio anual seguro & $\mathrm{N}^{\circ}$ socios pequeños - mediano* Precio anual \\
\hline
\end{tabular}




\begin{tabular}{|c|c|c|c|}
\hline \multirow[b]{3}{*}{$\begin{array}{l}\text { Ampliación de } \\
\text { oportunidades } \\
\text { económicas }\end{array}$} & \multirow{2}{*}{$\begin{array}{l}\text { medianos } \\
\text { Valor monetario } \\
\text { colaboración y apoyo }\end{array}$} & \multirow{2}{*}{$\begin{array}{l}\text { agrario } \\
\text { Tipo de interés préstamo } \\
\text { interbancario a entidades }\end{array}$} & \multirow{2}{*}{$\begin{array}{l}\text { seguro agrario } \\
\text { Valor monetario colaboración y apoyo * } \\
\text { Tipo de interés préstamo interbancario a } \\
\text { entidades }\end{array}$} \\
\hline & & & \\
\hline & $\begin{array}{l}\mathrm{Kg} \text { plátanos sueltos } \\
\text { recolectados }\end{array}$ & $\begin{array}{l}\text { Diferencial precio } \mathrm{Kg} \\
\text { plátano (dedo - manilla) }\end{array}$ & $\begin{array}{l}\mathrm{Kg} \text { plátanos sueltos } \text { recolectado } \\
\text { Diferencial precio } \mathrm{Kg} \text { plátano (dedo - } \\
\text { manilla) }\end{array}$ \\
\hline \multirow[t]{10}{*}{ Sostenibilidad } & $\begin{array}{l}\text { Kg plátanos donados } \\
+\mathrm{Kg} \mathrm{de} \mathrm{plátanos} \\
\text { vendidos }\end{array}$ & $\begin{array}{l}\text { Diferencial precio } \mathrm{Kg} \\
\text { plátano (ecológico } \\
\text { normal) }\end{array}$ & $\begin{array}{l}\text { Kg plátanos donados }+\mathrm{Kg} \text { de plátanos } \\
\text { vendidos }) * \text { Diferencial precio } \mathrm{Kg} \text { plátano } \\
\text { (ecológico - normal) }\end{array}$ \\
\hline & $\begin{array}{l}\mathrm{N}^{\mathrm{o}} \text { stakeholders que } \\
\text { lo valoran }\end{array}$ & $\begin{array}{l}\text { Precio anuncio } \\
\text { patrocinado en Facebook }\end{array}$ & $\begin{array}{l}\mathrm{N}^{\mathrm{o}} \text { stakeholders que lo valoran } * \text { Precio } \\
\text { anuncio patrocinado en Facebook }\end{array}$ \\
\hline & $\begin{array}{l}\mathrm{Kg} \text { plástico } \\
\text { reemplazados } * \\
\text { Ahorro } \mathrm{CO}_{2} \\
\end{array}$ & $\begin{array}{l}\text { Coste social del carbono } \\
(\$ / \text { Ton }) * \text { Tipo de } \\
\text { cambio }(€ / \mathrm{S}) \\
\end{array}$ & $\begin{array}{l}\mathrm{Kg} \text { plástico reemplazados } * \text { Ahorro } \mathrm{CO}_{2} * \\
\text { Coste social del carbono }(\$ / \text { Ton }) * \text { Tipo de } \\
\text { cambio }(€ / \mathrm{S})\end{array}$ \\
\hline & $\begin{array}{l}\mathrm{Kg} \\
\text { producidos } * \text { plátanos } \\
\mathrm{CO}_{2} \text { por producción } \\
\text { local }\end{array}$ & $\begin{array}{l}\text { Coste social del carbono } \\
(\$ / \text { Ton }) * \text { Tipo de } \\
\text { cambio }(€ / \mathrm{S})\end{array}$ & $\begin{array}{l}\mathrm{Kg} \text { plátanos producidos } * \text { Ahorro } \mathrm{CO} 2 \text { por } \\
\text { producción local } * \text { Coste social del carbono } \\
(\$ / \text { Ton }) * \text { Tipo de cambio }(€ / \mathrm{S})\end{array}$ \\
\hline & $\begin{array}{l}\text { Peso SAT en } \\
\text { producción agrícola } \\
\text { Canarias }\end{array}$ & $\begin{array}{l}\text { Importe Subvención } \\
\text { Plan de Desarrollo Rural } \\
\text { para Canarias fomento } \\
\text { del Desarrollo Rural } \\
\end{array}$ & $\begin{array}{l}\text { Peso SAT en producción agrícola Canarias * } \\
\text { Importe Subvención Plan de Desarrollo } \\
\text { Rural para Canarias fomento del Desarrollo } \\
\text { Rural }\end{array}$ \\
\hline & $\begin{array}{l}\mathrm{N}^{\mathrm{o}} \text { de } \\
\text { recibidas } * \text { visitas } \\
\mathrm{Kg} \mathrm{CO}_{2} \text { transporte } \\
\end{array}$ & $\begin{array}{l}\text { Coste social del carbono } \\
(\$ / \text { Ton }) * \text { Tipo de } \\
\text { cambio }(€ / \mathrm{S})\end{array}$ & $\begin{array}{l}\mathrm{N}^{\mathrm{o}} \text { de visitas recibidas } * \text { Ahorro } \mathrm{Kg} \mathrm{CO}_{2} \\
\text { transporte * Coste social del carbono } \\
(\$ / \text { Ton }) * \text { Tipo de cambio }(€ / \mathrm{S}) \\
\end{array}$ \\
\hline & $\begin{array}{l}\mathrm{N}^{\mathrm{o}} \text { h. charlas } * \mathrm{~N}^{\mathrm{o}} \\
\text { niños }\end{array}$ & $€ / \mathrm{h}$ Curso FGULL & $\mathrm{N}^{\mathrm{o}}$ h. charlas $* \mathrm{~N}^{\mathrm{o}}$ niño $* € / \mathrm{h}$ Curso FGULL \\
\hline & $\mathrm{N}^{\mathrm{o}}$ visitas $* \mathrm{~N}^{\mathrm{o}}$ niños & $\begin{array}{l}\text { Precio entrada parque } \\
\text { temático local }\end{array}$ & $\begin{array}{l}\mathrm{N}^{\mathrm{o}} \text { visitas } * \mathrm{~N}^{\mathrm{o}} \text { niños } * \text { Precio entrada parque } \\
\text { temático local }\end{array}$ \\
\hline & $\begin{array}{lr}\mathrm{Kg} & \text { dedos } \\
\text { recolectados } & * \\
\text { Ahorro Kg } & \mathrm{CO}_{2} \\
\text { producción } & \\
\end{array}$ & $\begin{array}{l}\text { Coste social del carbono } \\
(\$ / \text { Ton }) * \text { Tipo de } \\
\text { cambio }(€ / \mathrm{S})\end{array}$ & $\begin{array}{l}\mathrm{Kg} \text { dedos recolectados * Ahorro } \mathrm{Kg} \mathrm{CO}_{2} \\
\text { producción * Coste social del carbono } \\
(\$ / \text { Ton }) * \text { Tipo de cambio }(€ / \mathrm{S})\end{array}$ \\
\hline & $\begin{array}{l}\mathrm{Kg} \text { depositados } * \\
\text { Ahorro } \mathrm{CO}_{2} \text { forraje }\end{array}$ & $\begin{array}{l}\text { Coste social del carbono } \\
(\$ / \text { Ton }) * \text { Tipo de } \\
\text { cambio }(€ / S)\end{array}$ & $\begin{array}{l}\mathrm{Kg} \text { depositados } * \text { Ahorro } \mathrm{CO}_{2} \text { forraje * } \\
\text { Coste social del carbono }(\$ / \text { Ton }) * \text { Tipo de } \\
\text { cambio }(€ / \mathrm{S})\end{array}$ \\
\hline $\begin{array}{lr}\text { Reputación } & y \\
\text { ampliación } & \text { del } \\
\text { mercado } & \\
\end{array}$ & $\begin{array}{lr}\mathrm{N}^{\mathrm{o}} \text { proveedores } & \mathrm{y} \\
\text { entidades } & \mathrm{de} \\
\text { externalización } & \\
\end{array}$ & $\begin{array}{l}\text { Precio anuncio } \\
\text { patrocinado en Facebook }\end{array}$ & $\begin{array}{l}\mathrm{N}^{\mathrm{o}} \text { proveedores y entidades de } \\
\text { externalización * Precio anuncio patrocinado } \\
\text { en Facebook }\end{array}$ \\
\hline \multirow{2}{*}{$\begin{array}{l}\text { Fomento de } \\
\text { redes } \\
\text { informales y de } \\
\text { colaboración }\end{array}$} & $\begin{array}{lr}\mathrm{N}^{\mathrm{o}} \text { proveedores } & \mathrm{y} \\
\text { entidades } & \mathrm{de} \\
\text { externalización } & \\
\end{array}$ & $\begin{array}{l}\text { Cuota anual asociación } \\
\text { profesional }\end{array}$ & $\begin{array}{l}\mathrm{N}^{\mathrm{o}} \text { proveedores } \\
\text { externalización } \\
\text { profesional }\end{array}$ \\
\hline & $\begin{array}{l}\mathrm{N}^{\mathrm{o}} \text { trabajadores nivel } \\
\text { operativo }\end{array}$ & $\begin{array}{l}\text { Cuota anual Club } \\
\text { Deportivo Tenerife }\end{array}$ & $\begin{array}{l}\mathrm{N}^{\mathbf{o}} \text { trabajadores nivel operativo } * \text { Cuota } \\
\text { anual Club Deportivo Tenerife }\end{array}$ \\
\hline \multirow{2}{*}{$\begin{array}{l}\text { Confianza y } \\
\text { fluidez de } \\
\text { comunicación }\end{array}$} & $\begin{array}{l}\mathrm{N}^{\mathrm{o}} \text { stakeholders que } \\
\text { lo valoran }\end{array}$ & $\begin{array}{lr}\text { Salario } & \text { Mínimo } \\
\text { Interprofesional mensual }\end{array}$ & $\begin{array}{l}\mathrm{N}^{\mathrm{o}} \text { stakeholders que lo valoran } * \text { Salario } \\
\text { Mínimo Interprofesional mensual }\end{array}$ \\
\hline & $\%$ trabajadores & $\begin{array}{l}\text { Cuota anual seguro } \\
\text { médico }\end{array}$ & $\%$ trabajadores $*$ Cuota anual seguro médico \\
\hline $\begin{array}{l}\text { Reconocimiento } \\
\text { del trabajo }\end{array}$ & $\begin{array}{l}\mathrm{N}^{\mathrm{o}} \text { trabajadores } \\
\text { empaquetado }\end{array}$ & Precio cesta Navidad & $\begin{array}{l}\mathrm{N}^{\circ} \text { trabajadores empaquetado } * \text { Precio cesta } \\
\text { Navidad }\end{array}$ \\
\hline Formación & $\begin{array}{l}\mathrm{N}^{\mathrm{o}} \mathrm{h} \\
\text { recibida }\end{array}$ & €/h Curso FGULL & 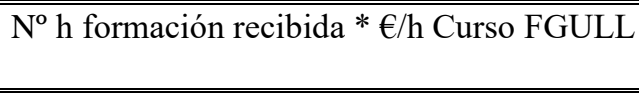 \\
\hline Flexibilidad & $\mathrm{N}^{\mathrm{o}}$ trabajadores & $\begin{array}{l}\text { Salario anual bruto }(2 \mathrm{~h} \\
\text { diarias apoyo })\end{array}$ & $\begin{array}{l}\mathrm{N}^{\mathrm{o}} \text { trabajadores } * \text { Salario anual bruto }(2 \mathrm{~h} \\
\text { diarias apoyo })\end{array}$ \\
\hline $\begin{array}{l}\text { Poder } \\
\text { decisión }\end{array}$ & $\begin{array}{l}\mathrm{N}^{\mathrm{o}} \\
\text { intermedios }\end{array}$ & Cuota anual autónomo & $\begin{array}{l}\mathrm{N}^{\mathrm{o}} \text { mandos intermedios }- \text { directivos } * \text { Cuota } \\
\text { anual autónomo }\end{array}$ \\
\hline
\end{tabular}




\begin{tabular}{|c|c|c|c|}
\hline & directivos & & \\
\hline $\begin{array}{l}\text { Igualdad } \\
\text { género }\end{array}$ & $\begin{array}{l}\text { Valor implicación y } \\
\text { sensibilización }\end{array}$ & $\begin{array}{l}\text { Valor para } \\
\text { stakeholder }^{(1)}\end{array}$ & Valor para el stakeholder \\
\hline \multirow{4}{*}{$\begin{array}{l}\text { Espíritu } \\
\text { cooperativo } \\
\text { solidaridad } \\
\text { interna }\end{array}$} & $\begin{array}{l}\mathrm{N}^{\circ} \text { socios pequeños - } \\
\text { medianos }\end{array}$ & $\begin{array}{l}\text { Cuota anual seguro } \\
\text { médico }\end{array}$ & $\begin{array}{l}\mathrm{N}^{\mathrm{o}} \text { socios pequeños }- \text { medianos } * \text { Cuota } \\
\text { anual seguro médico }\end{array}$ \\
\hline & $\begin{array}{l}\mathrm{N}^{\mathrm{o}} \text { stakeholders que } \\
\text { lo valoran }\end{array}$ & $\begin{array}{lll}\text { Cuota anual seguro } \\
\text { médico }\end{array}$ & $\begin{array}{l}\mathrm{N}^{\circ} \text { stakeholders que lo valoran } * \text { Cuota anual } \\
\text { seguro médico }\end{array}$ \\
\hline & $\begin{array}{l}\mathrm{N}^{\circ} \text { stakeholders que } \\
\text { lo valoran }\end{array}$ & $\begin{array}{l}\text { Cuota anual seguro } \\
\text { médico }\end{array}$ & $\begin{array}{l}\mathrm{N}^{\circ} \text { stakeholders que lo valoran } * \text { Cuota anual } \\
\text { seguro médico }\end{array}$ \\
\hline & $\%$ trabajadores & $\begin{array}{lll}\text { Cuota anual seguro } \\
\text { médico }\end{array}$ & $\%$ trabajadores $*$ Cuota anual seguro médico \\
\hline $\begin{array}{l}\text { Elección ética } \\
\text { de proveedores }\end{array}$ & Memoria RSC & $\begin{array}{l}\text { elaboración } \\
\text { RSC } \\
\end{array}$ & Precio elaboración memoria RSC \\
\hline $\begin{array}{l}\text { Proactividad e } \\
\text { innovación }\end{array}$ & $\begin{array}{l}\mathrm{N}^{\mathrm{o}} \text { stakeholders que } \\
\text { lo valoran }\end{array}$ & $\begin{array}{l}\text { Subvención concedida } \\
\text { por emprender }\end{array}$ & $\begin{array}{l}\mathrm{N}^{\mathrm{o}} \text { stakeholders que lo valoran } * \text { Subvención } \\
\text { concedida por emprender }\end{array}$ \\
\hline
\end{tabular}

(1) Se refiere al valor concreto para el grupo de interés. Este valor puede conocerse porque, en la entrevista en profundidad a los stakeholders (Retolaza et al., 2016), se incluye la pregunta: "Si tuviese que cuantificar en términos monetarios el valor que le aporta la SAT, ¿cómo lo aproximaría?, ¿podría poner un precio?” El interlocutor representativo del colectivo que valora la proactividad en la igualdad de género de la SAT respondió una cuantía específica a esta pregunta. Se consideró que su respuesta sería el mejor proxy.

\section{Conclusiones}

Los resultados alcanzados en este trabajo permiten comprobar que algunos de los intereses de los stakeholders de la entidad son compartidos con los de otras familias de la economía social cuyo valor social ha sido cuantificado en términos monetarios (Retolaza et al., 2015; Retolaza, Ruiz-Roqueñi y San-Jose, (2015). Para la medición de tales intereses comunes, se han propuesto en este trabajo indicadores y proxys similares para ciertas dimensiones del valor social percibido, aunque no para otras. Las métricas propuestas permiten avanzar en la necesaria labor de estandarización de la contabilidad social y suponen una contribución con respecto a trabajos de similar naturaleza, tanto por analizar variables que no habían surgido anteriormente como por profundizar en el estudio de otras que ya habían sido abordadas.

En particular, las métricas referidas a "formación" y "voluntariado", dentro de la variable de valor Respuesta social $^{35}$, a Empleabilidad y a "dinamización del medio rural", incluida en Sostenibilidad", son similares a las planteadas por Retolaza et al. (2015) y Retolaza, Ruiz-Roqueñi y San-Jose, 2015) para una fundación y una entidad pública, respectivamente ${ }^{37}$. Sin embargo, para Innovación e "intereses medioambientales" dentro de Sostenibilidad, en las que en Retolaza et al. (2015:28-29) se proponen proxys en términos de Gasto en I+D y de precios de mercado ${ }^{38}$, respectivamente, en este estudio se ha utilizado "subvenciones concedidas a la innovación por la Administración Pública" como aproximación financiera de la proactividad, y "coste social de la huella de carbono" para reflejar el valor social específico referido al medioambiente, por estimarse más cercanas a un enfoque de valor y de equidad intergeneracional.

El resto de las variables de valor obtenidas en este estudio, y medidas a través de los indicadores y proxys propuestos, son particulares para la entidad por razón de su objeto social, y alineadas con los fines atribuidos por el Real Decreto 1776/1981. A este respecto, los intereses de los socios integrados en Seguridad económica, vendrían a ser reflejo del objetivo económico de la organización ${ }^{39}$, estando las restantes variables de valor referidas al fin social. Concretamente, los objetivos de "dinamización del medio rural" o "prestación de servicios comunes", reconocidos jurídicamente, quedan recogidos en Sostenibilidad y Asesoramiento, respectivamente.

Han aflorado a su vez múltiples intereses de los colectivos con los que se relaciona la entidad que suponen un reconocimiento de su enfoque en la generación de valor social para la sostenibilidad, y no sólo a través de

35 En la Tabla 6, en la variable de valor Respuesta social, el interés “formación" queda recogido en las filas 10, 12, 13 y 15, y "voluntariado" en la número 11.

36 En la Tabla 6, el interés "dinamización del medio rural" queda recogido en la fila número 5 de la variable Sostenibilidad.

37 En concreto, se mide "formación" y "voluntariado" en términos de "número de horas" y "precio de cursos de similares características" o "salario hora", "empleabilidad" a través de "ahorro para la Administración Pública de la subvención", y "dinamización del medio rural" utilizando la proxy "plan de desarrollo rural".

38 Por ejemplo, precios de derechos de emisión de $\mathrm{CO}_{2}$ o precios de disposición final de residuos.

39 Tales intereses se han medido utilizando como proxys el valor razonable de activos similares en el espacio-temporal específico de la SAT de estudio. 
sus prácticas laborales ${ }^{40}$ o la política de compras a proveedores ${ }^{41}$, en particular: la Seguridad económica a entidades del tercer sector, medida a través de la certidumbre aportada en la toma de decisiones de consumo y ahorro a estos agentes; la ampliación de las oportunidades económicas a los colectivos más desfavorecidos, colocando productos de alimentación en el mercado a un precio asequible; el apoyo a la dimensión medioambiental de la sostenibilidad a través de acciones que suponen un ahorro directo o indirecto de la huella de carbono; o la sensibilización social de las costumbres agrícolas regionales.

Por último, podrían destacarse los valores de cooperativismo y solidaridad, reconocidos por los socios, trabajadores y proveedores, presentes en la entidad aun no configurándose jurídicamente como una cooperativa.

Los resultados de este trabajo son sólo un primer paso en la construcción de una base mínima de indicadores y aproximaciones financieras para la monitorización de la contribución a la sostenibilidad social de las SATs en el territorio español. En desarrollos posteriores sería necesario aplicar la metodología del SPOLY a un número representativo de estos agentes, para disponer de un número suficiente de casos que permitiera configurar un cuadro de variables de valor común a todos ellos, y lograr consensos intersubjetivos en relación con los outputs y proxys a ellas atribuidos para su estandarización.

\section{Referencias bibliográfícas}

Aguado, R., Alcaniz, L. \& Retolaza, J. L. (2015) A new role for the firm incorporating sustainability and human dignity. Conceptualization and measurement. Human Systems Management, № 3, Vol. 1, pp. 43-56.

Ariza-Montes, A., Ruíz-Lozano, M., Sianes, A., Fernández-Rodríguez, V., López Martín, M.C. y Tirado Valencia, P. (2018) Análisis del Retorno Social de la Inversión (SROI) del Programa ROMI de la Fundación Secretariado Gitano. Actas del XVII Congreso Internacional de Investigadores en Economía Social y Cooperativa - La Economía Social: transformaciones recientes, tendencias y retos de futuro. Toledo.

Ayuso, S. (2018) La medición del impacto social en el ámbito empresarial. Cátedra MANGO de RSC ESCI-UPF Documento de trabajo, $\mathrm{N}^{\circ} 26$.

Bassi, A. y Vincenti, G. (2015) Toward a new metrics for the evaluation of the social added value of social enterprises. CIRIEC-España, Revista de Economía Pública, Social y Cooperativa, № 83, pp. 9-42.

Bel Durán, P. (1995) Similitudes y diferencias entre las sociedades cooperativas agrarias y las Sociedades Agrarias de Transformación a la luz de los principios cooperativos tras el Congreso de Manchester. REVESCO. Revista de Estudios Cooperativos, $\mathrm{N}^{\circ}$ 61, pp. 107-126.

Berners -Lee, M. (2010) How Bad Are Bananas?: The carbon footprint of everything. London: Profile Books Ltd.

B Lab (2017) http://bcorporation.eu/.

Bono, E. (2012) El decrecimiento sostenible, crisis ecológico-económica, desigualdad y economía social. CIRIECEspaña, Revista de Economía Pública, Social y Cooperativa, № 76, pp. 180-196.

Bretos, I. y Marcuello, C. (2016) Viabilidad e impacto social y económico de las cooperativas en la globalización actual: revisión crítica de la literatura y agenda para la investigación futura. XVI Congreso Investigadores de Economía Social y Cooperativa. Economía Social: crecimiento económico y bienestar. Octubre.

Can Cet (2016) Balance del Bien Común (http://www.cancet.org).

Cátedra Cajasiete de Economía Social y Cooperativa (2019) Las SATs: fórmula preferida por los agricultores para asociarse en Canarias. Lunes Cooperativos.

Carbonell de Masy, R. y Paniagua, J. (1974) Grupos Sindicales de Cooperación. Estudios Cooperativos, № 32, pp. 1932.

Chaves, R. \& Monzón, J.L. (2012) Beyond the crisis: the social economy, prop of a new model of sustainable economic development. Service Business, № 6, vol. 1, pp. 5-26.

Chaves, R. y Monzón, J.L. (2018) La economía social ante los paradigmas económicos emergentes: innovación social, economía colaborativa, economía circular, responsabilidad social empresarial, economía del bien común, empresa social y economía solidaria. CIRIEC-España, Revista de Economía Pública, Social y Cooperativa, № 93, pp. 5-50.

CIRIEC-España (1995) Los principios cooperativos del Siglo XXI. Declaración de la Alianza Cooperativa Internacional sobre la Identidad Cooperativa aprobada en Manchester en el XXXI Congreso de la ACI. CIRIEC-España, Revista de Economía Pública, Social y Cooperativa, No 19. pp. 37-41.

Comisión Europea (2015) Métodos propuestos para la medición del impacto social en la legislación de la Comisión Europea y en la práctica relativa a FESE y EaSI., Luxemburgo, Comisión Europea - Dirección General de Empleo, Asuntos Sociales e Inclusión.

Cortina, A. (2009) Ética de la empresa: No sólo Responsabilidad Social. Revista Portuguesa de Filosofía, pp. 113-127.

Daly, H. E. (1973) Toward a Steady State Economy. San Francisco: W. H. Freeman and Company.

40 Recogido en Formación, Flexibilidad, o Poder de decisión.

41 Variable Elección ética de proveedores. 
Díaz, M., Marcuello, C. y Marcuello, C. (2012) Empresas sociales y evaluación del impacto social. CIRIEC-España, Revista de Economía Pública, Social y Cooperativa, No 75, pp. 179-198.

Duska, R.F., \& Ragatz, J.A. (2008) Purpose of Business. En Kolbo, R.W. (eds.) Purpose of Business, Los Angeles, USA: SAGE. Pp. 210-216.

Ebrahim, A., \& Rangan, V.K. (2010) The Limits of Nonprofit Impact: A Contingency Framework for Measuring Social Performance. Social Enterprise Initiative Harvard Business School Working Paper, № 10-099.

Etxezarreta, E., Mendiguren, J.C.P., Díaz, L. y Errasti, A. (2018) Valor social de las cooperativas sociales: aplicación del modelo poliédrico en la cooperativa para la acogida de menores Zabalduz S.Coop. CIRIEC-España, Revista de Economía Pública, Social y Cooperativa, № 93, pp. 155-180.

Felber, C. (2010). La Economía del Bien Común. Viena: Deusto.

Flores, D. y O Barroso, M.D.L. (2011) Desarrollo rural, economía social y turismo rural: un análisis de casos. CIRIECEspaña, Revista de Economía Pública, Social y Cooperativa, No 70, pp. 55-80.

Freeman, R.E. (1984) Strategic management a stakholder approach. Boston: Pitman.

Freeman, R.E., Wicks, A.C., \& Parmar, B. (2004) Stakeholder Theory and "The Corporate Objective Revisited. Organization Science, № 15, Vol. 3, pp. 364-369.

Friedman, M. (1970) The Social Responsibility of Business is to Increase its Profits. The New York Times Magazine, September. p.13.

Gadea, E. (1996) Análisis del régimen jurídico de las Sociedades Agrarias de Transformación. Asociación Internacional de Derecho Cooperativo, Vol. 25, pp. 33-53.

García-Gutiérrez, C. (1991) La economía social o la economía de las empresas de participación (las sociedades cooperativas y laborales). En VV.AA. (1991) En memoria de María Ángeles Gil Luezas. Madrid: Alfa Centauro, pp. 195-213.

Garriga, E. (2014) Beyond stakeholder utility function: stakeholder capability in the value creation process. Journal of Business Ethics, № 120, Vol. 4, pp. 489-507.

Gonzalo, J.A. y Pérez, J. (2017) Una propuesta de normalización relativa al valor añadido como medida alternativa de rendimiento empresarial. XIX Congreso Internacional AECA, Santiago de Compostela, septiembre.

Herzberg, F. (1996) Work and Nature of the Man. Nueva York: Crowell.

Honeyman, R., J.C. Gilbert, B., Houlahan, \& A. Kassoy (2014) The B Corp Handbook: How to Use Business as a Force for Good. Berrett-Koehler Publishers.

Husserl, E. (1990). Ideas pertaining to a pure phenomenology and to a phenomenological philosophy: studies in the phenomenology of constitution. Springer.

Instituto Canario de Estadística (2019) Canarias en Cifras 2016. Instituto Canario de Estadística.

Instituto Nacional de Estadística (2019) Anuario Estadístico de España 2018. Instituto Nacional de Estadística.

Kaufmann, A. y Gil Aluja, J. (1986) Introducción de la teoría de los subconjuntos borrosos a la gestión de las empresa. Santiago de Compostela, Spain: Milladoiro

Lescot, T. (2012) Huella de Carbono y Ciclo de Vida en la producción de plátano. II Jornadas de Transferencia de $I+D+i$ para una producción sostenible del plátano en las RUPs. Tenerife, octubre.

Lewin, K. (1946) Action research and minority problems. Journal of Social Issues, No 2, Vol. 4, pp. 34-46.

Macías, A.J. (2018) La economía social y el desarrollo sostenible, un camino común que marcan sus principios. Actas del XVII Congreso Internacional de Investigadores en Economía Social y Cooperativa, Toledo, octubre.

Maslow, A.H. (1954) Motivation and personality. Nueva York: Harper.

Mauleón, E. y Genovart, J. I. (2015) El capital y la aplicación de resultados en las sociedades agrarias de transformación: praxis y propuestas lege ferenda. REVESCO. Revista de Estudios Cooperativos, Segundo Cuatrimestre, № 118, pp. 148-179. DOI: 10.5209/rev_REVE.2015.n118.49060.

Meadows, D. (1998) Indicators and Information Systems for Sustainable Development. A Report to the Balaton Group. Netherlands: The Sustainable Institute.

Melé, D. (2009) The view and the purpose of the firm in Freeman's stakeholder theory. Philosophy of Management, $\mathrm{N}^{\mathrm{o}}$ 8, Vol. 3, pp. 3-13.

Ministerio de Agricultura, Pesca y Alimentación (2019) Informe Anual SAT 2018.

Mishan, Q. (2007) Cost benefit analysis. New York: Routledge.

Moldan, B., \& Dahl, A.L. (2007) Challenges to Sustainability Indicators. En Hák, T., Moldan, B., \& Dahl, A.L. (eds) Sustainability Indicators. A Scientific Assessment. London: Island Press, pp. 1-24.

Monzón, J.L. (2013) Empresas sociales y economía social: perímetro y propuestas metodológicas para la medición de su impacto socioeconómico en la UE. Revista de Economía Mundial, Vol. 35, pp. 21-45.

Monzón, J.L., Marcuello, C. y Nachar, P. (2013) Empresas sociales y economía social: propuestas metodológicas para la medición de su impacto socio-económico. Bruselas: CESE.

Mozas, A. y Bernal, E. (2006) Desarrollo territorial y economía social. CIRIEC-España, Revista de Economía Pública, Social y Cooperativa, $\mathrm{N}^{\mathrm{0}} 55$, pp. 125-140.

Nachar, P. (2013) Sociedades Cooperativas, una Aproximación desde la Responsabilidad Social Corporativa y el Desarrollo. Tesis Doctoral, Universidad de Zaragoza.

Neto, F. (2003) A New Approach to Sustainable Tourism Development: Moving Beyond Environmental Protection. DESA Discussion Paper, $\mathrm{N}^{\circ} 29$. 
Nordhaus, W.D. (2011) Estimates of the social cost of carbon: background and results from the rice - 2011 model. NBER Working Paper, $\mathrm{N}^{\circ} 17540$.

Nussbaum, M. (1997) Capabilities and Human Rights. Fordham Law Review, № 66, pp. 297-300.

Nussbaum, M. (2011) Creating Capabilities: The Human Development Approach. Cambridge: The Belknap Press of Harvard University Press.

Olsen, S., \& Galimidi, B. (2008) Catalog of Approaches to Impact Measurement: Assessing Social Impact in Private Ventures. Social Venture Technology Group.

Orden de 14 de septiembre de 1982, BOE núm. 242, de 9 de octubre.

Parasuraman, A., Berry, L.L., \& Zeithaml, V.A. (1988) SERVQUAL: A Multiple-Item Scale for Measuring Customer Perceptions of Service Quality. Journal of Retailing, N 64, Vol. 1, pp. 12-40.

Parasuraman, A., Berry, L.L., \& Zeithaml, V.A. (1991) Refinement and Reassessment of the SERVQUAL Scale. Journal of Retailing, $\mathrm{N}^{\circ}$ 67, Vol. 4, pp. 420-450.

Paz Canalejo, N. (1982) El nuevo estatuto reglamentario de las SAT y la reforma de la legalidad cooperativa. Agricultura y Sociedad, No 23, pp. 81-156.

Pearce, D. (1988) Economics, equity and sustainable development. Futures, № 20, pp. 598-605.

Polkinghorne, D.E. (1989) Phenomenological research methods. En Valle, R.S, \& Halling, S. (eds.) Existentialphenomenological perspectives in psychology: exploring the breadth of human experience. New York: Plenum Press.

Porter, M.E., \& Kramer, M.R. (2011) Creating Shared Value. Harvard Business Review, No 89, Vol. 1/2, pp. 62-77.

Poudel, S., Nyaupane, G.P., \& Budruk, M. (2016) Stakeholders' perspectives of sustainable Tourism development: A new approach to measuring outcomes. Journal of Travel Research, № 55, Vol 4, pp. 465-480.

Puentes, R. y Velasco, M.D.M. (2009) Importancia de las sociedades cooperativas como medio para contribuir al desarrollo económico, social y medioambiental, de forma sostenible y responsable. REVESCO. Revista de Estudios Cooperativos, Tercer Cuatrimestre, No 99, pp. 104-129.

Randle, E.J., \& Hoye, R. (2016) Stakeholder perception of regulating commercial tourism in Victorian National Parks, Australia. Tourism Management, No 54, pp. 138-149.

Real Decreto 1776/1981, de 3 de agosto, por el que se aprueba el Estatuto que regula las Sociedades Agrarias de Transformación, BOE núm. 194, de 14 de agosto.

Retolaza, J.L, Ruiz-Roqueñi, M. y San-Jose, L. (2015). Monetarizing the social value: theory and evidence. CIRIECEspaña Revista de Economía Pública, Social y Cooperativa, Nº 83, pp. 43-62.

Retolaza, J.L, Ruiz-Roqueñi, M., San-José, L. y Barrutia, J. (2014) Cuantificación del valor social: propuesta metodológica y aplicación al caso de Lantegi Batuak. Revista de servicios sociales, № 55, pp. 17-33.

Retolaza, J.L, Sánchez, P., Tarifa, P., Ruiz-Roqueñi, M., San-José, L. y Ayuso, S. (2015) Análisis del valor social de la Fundación Formació i Trebal: Una aproximación monetaria al cálculo del valor social. Cátedra Mango. Documento de trabajo, $\mathrm{N}^{\mathrm{o}} 22$.

Retolaza, J.L. y San-José, L. (2016) Contabilidad social para la sostenibilidad: modelo y aplicación. Revista de Contabilidad y Dirección, № 23, pp. 159-178.

Retolaza, J.L., San-José, L. y Ruiz-Roqueñi, M. (2016). Social Accounting for Sustainability: Monetizing the Social Value. Springer Briefs in Business, Springer.

Román-Cervantes, C. (2008) Las Sociedades Agrarias de Transformación en España: un análisis histórico. CIRIECEspaña, Revista de Economía Pública, Social y Cooperativa, № 63, pp. 65-87.

Román-Cervantes, C. (2008) Between solidarity and profit: the agricultural transformation societies in Spain, 1940 2000. Canada: Centre for the Study of Co-operatives - University of Saskatchewan.

Ruiz-Roqueñi, M. (2018) Valor emocional. Medición del Valor Social para la Sostenibilidad, Curso de Verano de la Universidad del País Vasco, 5 - 6 de julio, Universidad del País Vasco.

Salcedo, G. (2016) La huella de carbono en los forrajes de Cantabria (España). Conference Paper Innovación Sostenible en Pastos: hacia una Agricultura de Respuesta al Cambio Climático, pp. 159-165.

Tarde, G. (1902) Psicologie economique. Paris: Feliz Alcan.

Tomás, A. (2008) El desarrollo local sostenible en clave estratégica. CIRIEC-España, Revista de Economía Pública, Social y Cooperativa, $\mathrm{N}^{\mathrm{0}}$ 61, pp. 73-101

Tuan, M. (2008) Measuring and/or estimating social value creation: insights into eight integrated cost approaches. Bill and Melinda Gates Foundation University Press Working Paper, N ${ }^{\circ} \quad 12 / 15 / 08$. https://docs.gatesfoundation.org/Documents/www.-report-measeuring-estimating-social-value-creation.pdf.

Vargas-Vasserot, C. (2009) Las sociedades agrarias de transformación en España. Defectos legales y ventajas operativas. Revista Estudios Agrarios, № 42, pp. 75-107.

Vargas-Vasserot, C. (2012) Sociedades Agrarias de Transformación. Empresas agroalimentarias entre la economía social y la del mercado. Madrid: Dykinson.

UN (2002) Informe de la Cumbre Mundial sobre el Desarrollo Sostenible. Nueva York: Naciones Unidas.

UN (2012) The future we want. Resolution of General Assembly 66/288, 27 July.

UN (2015) Transforming our world: the 2030 Agenda for Sustainable Development. Resolution of the General Assembly A/RES/70/1, September.

UN (2017) Work of the Statistical Commission pertaining to the 2030 Agenda for Sustainable Development. Resolution of the General Assembly A/RES/71/313, 6 July. 
UN GLOBAL COMPACT/GRI/WBCSD (2015) SDG Compass: La guía para la acción empresarial en los ODS. http://sdgcompass.org/wp-content/uploads/2016/06/SDG_Compass_Spanish-one-pager-view.pdf. Fecha de último acceso: febrero de 2019.

UNTFSSE (2016) Realizing the 2030 Agenda through Social and Solidarity Economy. Position Statement. Julio. http://unsse.org/wp-content/uploads/2014/08/Final_Position-Paper-SSEandSDGs_UNTFSSE.pdf.

Utting, P. (2015) Realizing the 2030 Development Agenda through Social and Solidarity Economy. Paper prepared for the United Nations Task Force for Social and Solidarity Economy.

World Commission on Environment and Development (1987) Our Common Future. New York, USA.

WBCSD/IFC (2008) Medición de impacto - Marco metodológico: Metodología para entender el aporte del sector empresario a la sociedad. Ginebra: World Business Council for Sustainable Development/International Finance Corporation.

Zadeh, L.A. (1965) Fuzzy Sets. Information Control, No 8, pp. 338-353. 